NBER WORKING PAPER SERIES

\title{
STRUCTURAL ESTIMATION OF A MODEL OF SCHOOL CHOICES: THE BOSTON MECHANISM VS. ITS ALTERNATIVES
}

\author{
Caterina Calsamglia \\ $\mathrm{Chao} \mathrm{Fu}$ \\ Maia Güell \\ Working Paper 24588 \\ http://www.nber.org/papers/w24588 \\ NATIONAL BUREAU OF ECONOMIC RESEARCH \\ 1050 Massachusetts Avenue \\ Cambridge, MA 02138 \\ May 2018
}

We thank Yuseob Lee for excellent research assistance. We thank the editor and five anonymous referees for their suggestions. We thank the staff at IDESCAT, especially Miquel Delgado, for their help in processing the data. We thank Steven Durlauf, Jeremy Fox, Amit Gandhi, John Kennan and Chris Taber for insightful discussions. We thank participants at the Cowles conference, Barcelona GSE summer forum and ASSA 2016, and workshop participants at ASU, Rice, Royal Holloway, Stanford, Virginia Tech, UChicago and UCL for helpful comments. The authors acknowledge support from a grant from the Institute for New Economic Thinking for the Human Capital and Economic Opportunity Global Working Group. The views expressed in this paper are those of the authors and not necessarily those of the funders or persons named here. Calsamiglia acknowledges support from the European Research Council through the ERC Grant 638893, and the the Spanish Ministry of Science and Innovation (ECO2014-53051-P), the Generalitat de Catalunya (2014 SGR 515), and Severo Ochoa. Guell acknowledges support from the Spanish Ministry of Science and Innovation (ECO-ECO2014-59225-P and ECO2017-89240P). All errors are ours. The views expressed herein are those of the authors and do not necessarily reflect the views of the National Bureau of Economic Research.

NBER working papers are circulated for discussion and comment purposes. They have not been peer-reviewed or been subject to the review by the NBER Board of Directors that accompanies official NBER publications.

(C) 2018 by Caterina Calsamglia, Chao Fu, and Maia Güell. All rights reserved. Short sections of text, not to exceed two paragraphs, may be quoted without explicit permission provided that full credit, including $\odot$ notice, is given to the source. 
Structural Estimation of a Model of School Choices: the Boston Mechanism vs. Its Alternatives Caterina Calsamglia, Chao Fu, and Maia Güell

NBER Working Paper No. 24588

May 2018

JEL No. I0,J0

\begin{abstract} average welfare by 460 euros.

Caterina Calsamglia

UAB-Barcelona GSE

Edifici B, Campus de Bellaterra

08193 Bellaterra

ccalsamig@gmail.com

Chao $\mathrm{Fu}$

Department of Economics

University of Wisconsin - Madison

1180 Observatory Drive Madison,

WI 53706

and NBER

cfu@ssc.wisc.edu

\author{
Maia Güell \\ University of Edinburgh \\ Economics \\ 50 George Square \\ Edinburgh EH8 9JY \\ UK \\ and FEDEA \\ maia.guell@gmail.com
}

We model household choice of schools under the Boston mechanism (BM) and develop a new method, applicable to a broad class of mechanisms, to fully solve the choice problem even if it is infeasible via the traditional method. We estimate the joint distribution of household preferences and sophistication types using administrative data from Barcelona. Counterfactual policy analyses show that a change from BM to the Deferred Acceptance mechanism would decrease average welfare by 1,020 euros, while a change to the top trading cycles mechanism would increase

A data appendix is available at http://www.nber.org/data-appendix/w24588 


\section{Introduction}

Designed to broaden households' access to schools beyond their neighborhoods, public school choice systems have been increasingly adopted in many countries. ${ }^{1}$ The quality of schools to which students are assigned can have significant long-term effects for individual families as well as important implications on efficiency and equity for a society. $^{2}$ How to assign students to schools is of key interest among policy makers and researchers.

One important debate centers around the popular Boston mechanism (BM), which is vulnerable to manipulation (Abdulkadiroğlu and Sönmez (2003)). Some cities, including Boston, have replaced BM with less manipulable mechanisms such as the student-proposing deferred acceptance mechanism (DA) (Gale and Shapley (1962)). ${ }^{3}$ However, the efficiency and equity comparison between BM and its alternatives remains an open question.

To answer this question, one needs to quantify two essential but unobservable factors underlying households' choices, which is what we do in this paper. The first factor is household preferences, indispensable for comparing welfare across mechanisms even if household choices were observed under each. Moreover, as choices are often not observed under counterfactual scenarios, one needs to predict how households would behave. The knowledge of household preferences alone is not enough for this purpose. Although BM gives incentives for households to act strategically, there may exist non-strategic households that simply rank schools according to their true preferences. ${ }^{4}$ A switch from BM to DA, for example, will induce behavioral changes only among strategic households. The knowledge about the distribution of household types (strategic or non-strategic) thus becomes a second essential factor.

We develop a model of school choices under BM by households who differ in both

\footnotetext{
${ }^{1}$ Some papers explore changes in families' school choice sets to study how school choice affect students' achievement, e.g., Abdulkadiroğlu et al. (2010), Deming et al. (2014), Hastings et al (2009), Lavy (2010), Mehta (2013) and Walters (2013). Other studies focus on how the competition induced by school choices affects school performance, e.g., Hoxby (2003) and Rothstein (2006).

${ }^{2}$ See Heckman and Mosso (2014) for a comprehensive review of the literature on human development and social mobility.

${ }^{3}$ See Abdulkadiroğlu et al. (2005) for the Boston reform; and Pathak and Sönmez (2013) for switches in other cities to less-manipulable mechanisms.

${ }^{4}$ There is direct evidence that both strategic and non-strategic households exist. For example, Abdulkadiroğlu et al. (2006) show that some households in Boston obviously failed to strategize. Calsamiglia and Güell (2014) prove that some households obviously behave strategically.
} 
their preferences for schools and their strategic types. Non-strategic households fill out application forms according to their true preferences. Strategic households take admissions risks into account to maximize their expected payoffs. A household's expected payoff depends on how it selects and ranks schools on its application list. The standard way to solve this problem selects the best permutation out of the set of schools. This method is applicable only when the choice set is small because the dimensionality grows exponentially with the number of schools. We utilize two unexploited properties of most allocation mechanisms, and show that the full optimization problem can be effectively solved via backward induction even when the household faces a large choice set. This solution method is applicable to a wide range of mechanisms, covering most mechanisms studied in the literature.

We apply our model to a rich administrative data set from Barcelona, where a BM system has been used to allocate students across over 300 public schools. Between 2006 and 2007, there was a drastic change in the official definition of school zones that significantly altered the set of schools a family had priorities for. We estimate our model using the 2006 pre-reform data via simulated maximum likelihood, and conduct an out-of-sample validation using the 2007 post-reform data. The model matches the data in both years.

In counterfactual policy experiments, we assess the performance of two truthrevealing alternatives to BM: DA and the top trading cycles mechanism (TTC). ${ }^{5}$ An average household would lose by an amount equivalent to 1,020 euros in a BM-to-DA change, and benefit by 460 euros in a BM-to-TTC change. A BM-to-DA change is more likely to benefit those who live in higher-school-quality zones, hence enlarging the cross-zone inequality. In a BM-to-TTC change, the quality of the school zone a household lives in does not impact its chance to win or to lose. While TTC enables $59 \%$ of households whose favorite schools are out of their zones to attend such schools, this fraction is only $47 \%$ under BM and $42 \%$ under DA.

We contribute to the literature on the design of centralized choice systems initiated by Balinski and Sönmez (1999) for college admissions, and Abdulkadiroğlu and Sönmez (2003) for public school choices, the latter leading to debates on BM. Some suggest that BM creates an equity problem as non-strategic parents may be disadvantaged by strategic ones (e.g., Pathak and Sönmez (2008)). Using Boston data under

\footnotetext{
${ }^{5}$ TTC was introduced by Shapley and Scarf (1974) and adapted by Abdulkadiroğlu and Sönmez (2003).
} 
BM, Abdulkadiroğlu et al. (2006) find that households that obviously failed to strategize were disproportionally unassigned. Calsamiglia and Miralles (2014) show that under certain conditions, the only equilibrium under $\mathrm{BM}$ is the one in which families apply for and are assigned to in-zone schools. Chen and Sönmez (2006) and Ergin and Sönmez (2006) show that DA is more efficient than BM in complete information environments. Abdulkadiroğlu et al. (2011), Featherstone and Niederle (2011), and Miralles (2008) provide examples where BM is more efficient than DA. ${ }^{6}$

Empirical studies that quantify the differences between alternative mechanisms have been sparse. ${ }^{7}$ He (2014) estimates an equilibrium model under BM. Under certain assumptions, he estimates household preferences without specifying the distribution of household sophistication types. This approach imposes fewer presumptions on the data, but restricts the model's ability to compare across mechanisms. Developed independently at roughly the same time as our paper are Hwang (2015) and Agarwal and Somaini (2016). Hwang (2015) set-identifies household preferences assuming certain simple rules on behavior. Assuming all households are strategic, Agarwal and Somaini (2016) interpret a household's submitted report as a choice of a probability distribution over assignments, which naturally corresponds to choosing the best permutation of schools. ${ }^{8}$ As in our paper, they also exploit the observed assignment outcomes and estimate household preferences without having to solve for the equilibrium. They show that a class of mechanisms can be consistently estimated and establish conditions under which preferences are non-parametrically identified. In the application, they estimate a parametric model using data from Cambridge, where each household can rank up to 3 programs out of 13 . The authors propose an estimation method based on Gibbs sampling, in which one initiates the procedure by solving for the best permutation for each household, but avoids having to compute the likelihood that a report is optimal during the estimation.

Our paper complements well the three papers mentioned above. We develop a solution method applicable to a wide range of choice mechanisms, which efficiently solves household problems that are unmanageable via the standard method. This new solution method can significantly expand the scope of empirical research on choice

\footnotetext{
${ }^{6}$ Some recent studies challenge the robustness of the results from Abdulkadiroğlu et al. (2011), e.g., Troyan (2012), Akyol (2014) and Lu (2015).

${ }^{7}$ With a different focus, Abdulkadiroğlu et al. (2014) show the benefits of centralizing school choice procedures.

${ }^{8}$ In an extension, they allow for the existence of both strategic and non-strategic households.
} 
mechanisms. We show evidence suggesting the coexistence of strategic and nonstrategic households, and estimate both household preferences and the distribution of strategic types in a parametric model. The rich variations in our data allow us to form a more comprehensive view of the alternative mechanisms in terms of not only the overall household welfare but also cross-neighborhood inequality. Moreover, we are able to validate our model using data after a sharp reform, which we view as a positive message for empirical research that compares different mechanisms via structural models and counterfactual analyses.

Researchers have used out-of-sample fits for model validation, exploiting random social experiments (Wise (1985), Lise et al. (2005), Todd and Wolpin (2006)), lab experiments (Bajari and Hortacsu (2005)), or regime shifts (McFadden and Talvitie (1977), Pathak and Shi (2014)). ${ }^{9}$ Some studies, including our paper, deliberately hold out data for validation purposes, e.g., Lumsdaine et al. (1992), Keane and Moffitt (1998) and Keane and Wolpin (2007).

The next section describes the background. Section 3 describes the model. Section 4 explains our estimation and identification strategy. Section 5 describes the data. Section 6 presents the estimation results. Section 7 conducts counterfactual experiments, followed by the conclusion. The appendix contains further details and additional tables.

\section{Background}

\subsection{The Public School System in Barcelona}

The public school system consists of over 300 public or semi-public schools. Public schools are fully financed by the government and free to attend. The operation of public schools follows government rules. All public schools are largely homogenous in teacher assignment, infrastructure, curricula, and funding per pupil. Semi-public schools are run privately, have more autonomy, and are allowed to charge service fees. On average, of the total funding for semi-public schools, $63 \%$ is from the government, $34 \%$ from service fees, and $3 \%$ from private sources. All public and semi-public schools are subject to the same national limit on class size; and have to unconditionally accept and only accept students assigned to them via the centralized procedure. Outside

\footnotetext{
${ }^{9}$ See Keane, Todd and Wolpin (2011) for a comprehensive review.
} 
of the system, there are private schools, accounting for only $4 \%$ of all schools in Barcelona. Private schools receive no public funding, are subject to few restrictions and do not participate in the centralized school choice program. ${ }^{10}$

\subsection{School Choice within the Public School System}

Families get into the public school system via a centralized procedure, in which almost all families participate. ${ }^{11}$ Every April, participating families with a child who turns 3 in that calendar year submit a ranked list of up to 10 schools. ${ }^{12}$ Assignment is via a Boston mechanism. The result is made public between April and May; and enrollment happens in September. If a school is over-demanded, applicants are prioritized according to government rules. Applicants can get priority points for the presence of a sibling in the same school (40 points), in-zone schools (30 points), and some family/child characteristics (e.g., disability (10 points)). Ties in total priority scores are broken through a fair lottery.

Transferring to a different school within the public system is feasible only if the receiving school has a free seat, which is nearly impossible for popular schools. In preschool-to-primary-school transitions, a student has the priority to stay in the same school she enrolled for preschool. Moreover, students are given priorities to specific secondary schools based on their primary schools.

\subsection{The 2007 Re-Definition of Zones}

Before 2007, Barcelona was divided into fixed zones. Families had 30 priority points for every in-zone school and 0 for out-of-zone schools, regardless of distance. ${ }^{13}$ In 2007 , a family's school zone was redefined as the smallest area around its residence that covered the closest 3 public and 3 semi-public schools. ${ }^{14}$ The reform was announced

\footnotetext{
${ }^{10}$ For this reason, information on private schools is very limited. Given the lack of information and the small fraction of schools they account for, we treat private schools as part of the (exogenous) outside option.

${ }^{11}$ In 2007 , over $95 \%$ of families with a 3 -year old child in Barcelona participated.

${ }^{12}$ Applications after the deadline can only be considered after all on-time applicants have been assigned.

${ }^{13}$ Before 2007, a family had priorities for a set of public schools defined by its public-school zone, and a set of semi-public schools defined by its semi-public-school zone. Throughout the paper, in-zone schools refer to the union of these two sets.

${ }^{14}$ There were over 5,300 zones under this new definition (Calsamiglia and Güell (2014)).
} 
abruptly on March 27th, 2007; families were informed via mail by March 30th and had to submit their lists by April 20th.

\section{Model}

\subsection{Primitives}

There are $J$ (public, semi-public) schools distributed across various zones in the city. There is a continuum of households of measure 1 (we use the words household, applicant, student and parent interchangeably). Each household submits an ordered list of schools. Then a centralized procedure assigns students according to their applications, school capacity and a priority structure. ${ }^{15}$ One can choose either the school one is assigned to or the outside option.

Each school $j$ has a location $l_{j}$, a vector $w_{j}$ of observable characteristics, and a characteristic $\zeta_{j}$ observable to households but not the researcher. ${ }^{16}$ No school can accommodate all students, but each student is guaranteed a seat in the system.

Household $i$ has characteristics $x_{i}$, a location $l_{i}$, idiosyncratic tastes for schools $\epsilon_{i}=\left\{\epsilon_{i j}\right\}_{j}$, and a type $T \in\{0,1\}$ (non-strategic or strategic). Households know their tastes and types, which are unobservable to the researcher. The vector $\epsilon_{i}$ is independent of $\left(x_{i}, l_{i}\right)$ and follows an i.i.d. distribution $F_{\epsilon}(\epsilon) .{ }^{17}$ The fraction of strategic households varies with household characteristics and locations, $\lambda\left(x_{i}, l_{i}\right)$. Conditional on observables, the two types differ only in their behaviors, specified later.

Remark 1 We do not take a stand on why some households are (non)strategic. This would be critical if a policy change may affect the fraction of strategic households. It's less concerning for us because we aim at investigating the impact of replacing BM with some truth-revealing mechanisms, under which all households will rank schools according to their true preferences. Once we recover household preferences and the

\footnotetext{
${ }^{15}$ Since almost all families participate in the application procedure in reality, we assume that the cost of application is zero and that all families participate. This is in contrast with the case of the costly college application, e.g., Fu (2014).

${ }^{16}$ We assume that households have full information about schools. Our data do not allow us to separate preferences from information frictions. Some examples using experiments to study how information affects schooling choices include Hastings and Weinstein (2008) and Jensen (2010).

${ }^{17}$ Each component of $\epsilon_{i}$ follows $N\left(0, \sigma_{\epsilon}^{2}\right)$.
} 
(current) distribution of types, we can compare the current regime with truth-revealing alternatives without the need to know how household types are determined.

We normalize the ex-ante value of the outside option to 0, so that a household's evaluation of each school is relative to its outside option. Let $d_{i j}$ be the distance between household $i$ and school $j$, and $d_{i}=\left\{d_{i j}\right\}_{j}$. Household $i$ 's utility from attending school $j$ is given by, ${ }^{18}$

$$
u_{i j}=U\left(w_{j}, x_{i}, d_{i j}, \zeta_{j}\right)+\epsilon_{i j}
$$

Between application and enrollment (about 6 months), the value of the outside option is subject to a shock $\eta_{i} \sim$ i.i.d. $N\left(0, \sigma_{\eta}^{2}\right)$, e.g., a wage shock that changes one's ability to pay for the private school. A household knows the distribution of $\eta_{i}$ before application, and observes $\eta_{i}$ afterwards. With $\eta_{i}$, applying for schools in the public system provides an option value for households. These shocks also rationalize the data fact that some households opted out despite being assigned to their first choices.

\subsection{Priority and Assignment}

Priority Scores: Let $z_{l}$ be the zone that contains location $l, I\left(l_{i} \in z_{l_{j}}\right)$ indicate whether $i$ lives in school $j$ 's zone, and $\operatorname{sib}_{i j} \in\{0,1\}$ indicate whether $i$ has some sibling enrolled in $j .{ }^{19}$ Household $i$ 's priority score for school $j\left(s_{i j}\right)$ is given by

$$
s_{i j}=x_{i}^{0} a+b_{1} I\left(l_{i} \in z_{l_{j}}\right)+b_{2} \operatorname{sib}_{i j}
$$

where $a$ is the vector of points based on demographics. In Barcelona, a student's priority score of her first choice carries over for all schools on her application. ${ }^{20}$ We take this feature into account in our analyses. Implied by (1), multiple households may tie in their priority scores. If a school is over-demanded, households are ranked first by their scores, tied households are ranked by random lottery numbers drawn after applications are submitted.

\footnotetext{
${ }^{18}$ A likelihood ratio test does not favor a more complex model with zone characteristics added to the utility function. Following the literature on choice mechanisms, we abstract from peer effects and social interactions (see Epple and Romano (2011) and Blume et. al (2011) for reviews). The major complication is the multiple equilibria problem arising from peer effects and social interactions, even under DA or TTC.

${ }^{19}$ Characteristics $x_{i}$ consists of demographics $x_{i}^{0}$ and the vector $\left\{\operatorname{sib}_{i j}\right\}_{j=0}^{J}$.

${ }^{20}$ For example, if a student lists an in-zone sibling school as her first choice, she carries $x_{i}^{0} a+b_{1}+b_{2}$ for all the other schools she listed.
} 
The BM Procedure: Schools are gradually filled up over $R<J$ rounds, where $R$ is the maximum length of an application list.

Round 1: For each school, consider only the students who have listed it as their first choice and assign seats to them one at a time following their priority scores from high to low (with random numbers as tie-breakers) until there is either no seat left or no student left who has listed it as her first choice.

Round $r \in\{2,3, \ldots, R\}$ : Only the $r^{\text {th }}$ choices of the students not previously assigned are considered. For each unfilled-up school, assign the remaining seats to these students one at a time following their priority scores and tie-breaking lottery numbers until there is either no seat left or no student left who has listed it as her $r^{\text {th }}$ choice. The procedure terminates after any step $r \leq R$ when every student is assigned, or if the only students who remain unassigned listed no more than $r$ choices. A student who remains unassigned after the procedure ends can propose a leftover school and be assigned to it.

Admissions probabilities to each school $j$ can be characterized by a triplet $\left(\bar{r}_{j}, \bar{s}_{j}, c u t_{j}\right)$, where $\bar{r}_{j}$ is the round at which $j$ is filled up $\left(\bar{r}_{j}>R\right.$ if $j$ is a leftover school), $\bar{s}_{j}$ is the priority score for which lottery numbers are used to break ties for $j$ 's slots, cut $_{j}$ is the cutoff of the lottery number for admission to $j$. School $j$ will admit any $r^{\text {th }}$-round applicant before $\bar{r}_{j}$, any $\bar{r}_{j}^{t h}$-round applicant with $s_{i j}>\bar{s}_{j}$, and any $\bar{r}_{j}^{t h}$ round applicant with score $\bar{s}_{j}$ and random lottery higher than $c u t_{j}$; and it will reject any other applicant. Once the random lottery numbers are drawn, admissions are fully determined. When making its application decision, a household knows $S_{i} \equiv\left\{s_{i j}\right\}_{j}$ but not its random number, which makes admissions uncertain in many school-round cases. The assignment procedure implies that the admissions probability is (weakly) decreasing in $s_{i j}$ in each round, and is (weakly) decreasing over rounds for all scores. In particular, the admissions probability to a school in Round $r+1$ for the highest priority score is (weakly) lower than that for the lowest score in Round $r$.

\subsection{Household Problem}

We start with the enrollment problem. After seeing the post-application shock $\eta_{i}$ and the assignment result, $i$ chooses between the school it is assigned to and the outside option. The expected value of being assigned to school $j$ is

$$
v_{i j}=E_{\eta_{i}} \max \left\{u_{i j}, \eta_{i}\right\}
$$


If rejected by all schools on its list, $i$ can opt for a school that it prefers the most among the leftover schools ( $i$ 's backup). The value $\left(v_{i 0}\right)$ of being assigned to its backup school is given by

$$
v_{i 0}=\max \left\{v_{i j}\right\}_{j \in l e f t o v e r s}
$$

\subsubsection{Application: Non-Strategic Households}

A non-strategic household lists schools according to its true preferences $\left\{v_{i j}\right\}_{j}$. Without further assumptions, any list of length $n(1 \leq n \leq R)$ that consists of the ordered top $n$ schools according to $\left\{v_{i j}\right\}_{j}$ is consistent with non-strategic behavior, which makes the prediction of allocation outcomes ambiguous. To avoid such a situation, we impose the following weak requirement: suppose household $i$ ranks its backup school as its $n_{i}^{*}$-th favorite, then the length of $i$ 's application list $n_{i}$ is such that

$$
n_{i} \geq \min \left\{n_{i}^{*}, R\right\}
$$

That is, when there are still slots left on its application form, a non-strategic household will list at least up to its backup school. ${ }^{21}$

Let $A_{i}^{0}=\left\{a_{1}^{0}, \ldots, a_{n_{i}}^{0}\right\}$ be an application list for non-strategic $(T=0)$ household $i$, where $a_{r}^{0}$ is the ID of the $r^{t h}$-listed school and $n_{i}$ satisfies (4). The elements in $A_{i}^{0}$ are given by

$$
\begin{aligned}
& a_{1}^{0}=\arg \max _{j}\left\{v_{i j}\right\}_{j} \\
& a_{r}^{0}=\arg \max _{j}\left\{v_{i j} \mid j \neq a_{r^{\prime}<r}\right\}_{j}, \text { for } 1<r \leq \min \left\{n_{i}^{*}, n_{i}\right\} .
\end{aligned}
$$

The $r^{\text {th }}$-listed school is one's $r^{\text {th }}$ favorite for the entire list if $n_{i}<n_{i}^{*}$, and for the first $n_{i}^{*}$ schools if the $n_{i} \geq n_{i}^{*}{ }^{22}$ Define $\mathbf{A}^{0}\left(x_{i}, \epsilon_{i}, l_{i}\right)$ as the set of lists that satisfy (4) and (5) for a non-strategic household with $\left(x_{i}, \epsilon_{i}, l_{i}\right)$. If $n_{i}^{*} \geq R$, the set $\mathbf{A}^{0}(\cdot)$ is a singleton, and the length of the list $n_{i}=R$. If $n_{i}^{*}<R$, all lists in the set $\mathbf{A}^{0}(\cdot)$ are identical up to the first $n_{i}^{*}$ elements and imply the same outcome.

\footnotetext{
${ }^{21}$ See the online appendix for further discussions about Condition (4).

${ }^{22}$ We do not require that schools listed after one's backup school be ranked, which is a weaker assumption than otherwise.
} 


\subsubsection{Application: Strategic Households}

Taking admissions probabilities as given, a strategic household maximizes its expected payoff. ${ }^{23}$ This payoff depends on not only which schools are listed but also how they are ordered. ${ }^{24}$ Therefore, the standard (direct) solution is to choose the best permutation of schools. Formally, let $\mathbf{P}(J ; R)$ be the set of all possible permutations of size 1 to $R$ out of elements in $J$, and $|\mathbf{P}(J ; R)|$ be its size. The standard solution is given by

$$
\max _{A \in \mathbf{P}(J ; R)} \pi\left(A, S_{i}, x_{i}, l_{i}, \epsilon_{i}\right),
$$

where $\pi(A, \cdot)$ is the expected value of list $A$. Choosing the best permutation has been feasible in previous studies because choice sets $(J)$ were small in those studies. When $J$ is relatively big and $R$ is beyond $1, \mathbf{P}(J ; R)$ soon becomes unmanageably large. In the case of Barcelona, with $J=317$ and $R=10,|\mathbf{P}(J ; R)|$ is over $8.9 \times 10^{24}$.

We develop a solution method to break the curse of dimensionality and fully solve the strategic household's problem, which is applicable to a broad class of mechanisms, referred to as the class under consideration from now on. ${ }^{25}$ Some examples in this class include BM, constrained and unconstrained DA, first preference first, Chinese parallel, and variants or hybrids of the above. ${ }^{26}$ The solution utilizes the following two unexploited properties that are intrinsic of these mechanisms.

(1) Sequentiality: Although the entire application list is submitted all at once, the ranked schools on the list are considered sequentially in the procedure. During the assignment, the $r^{t h}$-listed school $\left(a_{r}\right)$ is relevant only if one is rejected by all previously listed schools. Therefore, $a_{r}$ should be one's best choice contingent on reaching that stage, implying that the problem can be solved via backward induction.

(2) Reducible History: Being rejected by previously listed schools may carry information about one's probability of being assigned to $a_{r}$, but the information can be fully summarized by objects much simpler than the list $\left(a_{1}, \ldots a_{r-1}\right)$. Therefore,

\footnotetext{
${ }^{23}$ It is standard to assume that households take admissions probabilities as given, e.g., Abdulkadiroğlu et al. (2011), Hatfield et al. (2014), Azevedo and Hatfield (2015), Azevedo and Leshno (2015), Agarwal and Somaini (2016), and Kojima (2015).

${ }^{24}$ We assume that strategic households are fully rational because it is a clear baseline. As a justification, BM has been practiced in Barcelona for over 20 years and very familar to households. A more flexible model would allow for partially-informed types, which is a straight-forward extension to our framework but will impose great challenges for identification. We leave it for future work.

${ }^{25}$ Agarwal and Somaini (2016) study the same class of mechanisms.

${ }^{26}$ For example, the Cambridge mechanism, serial dictatorship and the Pan London Admissions.
} 
the problem involves a state space with a dimension much lower than $|\mathbf{P}(J ; R)|{ }^{27}$ In particular, as we show in the online appendix, with some differences in specifics, mechanisms in the class under consideration has the following feature. After being rejected by $\left(a_{1}, \ldots a_{r-1}\right), i$ will be admitted to $a_{r}$ if $a_{r}$ still has seats and if $i$ is ranked high enough among those being considered. The latter is fully determined by $i$ 's priority and random lottery number for $a_{r}$. Among the two factors, $i$ 's priority for $a_{r}$ is determined by pre-determined characteristics, and, in some instances, the rank position of the school on $i$ 's list (i.e., $r$ ); but it is independent of the other schools on the list. ${ }^{28}$ One's lottery number is drawn after the application, unknown to the applicant when making her decisions. In the case where a household has a single lottery number across all tie-breaking cases, correlation arises between the probabilities of being admitted to the listed schools: being rejected by $a_{1}$ due to losing the lottery for $a_{1}$ reveals that one's lottery number is below $c u t_{a_{1}}$, being rejected again by $a_{2}$ due to losing the lottery for $a_{2}$ reveals that one's lottery number is below $\min \left\{c u t_{a_{1}}, c u t_{a_{2}}\right\}$, and so on. However, other than this, $\left(a_{1}, \ldots a_{r-1}\right)$ bears no information that is payoff relevant for one's decision on $a_{r}$. Therefore, the dimensionality can be reduced considerably. Consider an example where one can list up to 3 schools out of 12 , under a standard BM. Suppose the numbers of schools filled up in Rounds 1 to 3 are $(5,4,3)$. The dimensionality is $|\mathbf{P}(12 ; 3)|=1,464$ in the direct solution, while it is bounded from the above by 150 in our solution.

Given sequentiality, we will explain how to derive a strategic household's optimal applications list $A_{i}^{1}=\left\{a_{i 1}^{1}, \ldots a_{i R}^{1}\right\}$ via backward induction in general. Then, we will use BM as an example to show the evolution of the state variables involved in the induction, utilizing the property of reducible history. The online appendix proves that this method fully solves the problem, formally describes the dimensionality involved in the solution, and explains applications of this method to other mechanisms in the class under consideration. Readers not interested in the details can skip to the next section.

\footnotetext{
${ }^{27}$ The dimensionality of the direct solution is the same as that of a backward induction where all details of the list $\left(a_{1}, \ldots, a_{r-1}\right)$ bear information relevant for $a_{r}$, which is not the case. That is, the direct method makes the problem unnecessarily complicated.

${ }^{28}$ One exception is the BM in Barcelona and Spain in general, where priorities for all listed schools are determined by the priority for the school ranked first. This makes the case in Spain more complicated than regular cases, which can nevertheless be solved efficiently using our method.
} 
Solution via Backward Induction Let $\digamma_{i}^{r} \equiv \digamma_{i}\left(a_{1}, \ldots a_{r-1}\right)$ be the information relevant for Round $r$ that is contained in the history of $i$ being rejected by $\left(a_{1}, \ldots a_{r-1}\right)$. Let $p_{j}^{r}\left(S_{i} \mid \digamma_{i}^{r}\right)$ be the probability of being admitted to $j$ for a household with scores $S_{i}$ and $j$ as its $r^{\text {th }}$ choice. The contents of $F_{i}^{r}$ and the determination of $p_{j}^{r}(\cdot)$ vary across mechanisms and depend on the detailed specification of priorities and the usage of lottery numbers in ranking applicants. However, in the class of mechanisms under consideration, given $\left(S_{i}, x_{i}, l_{i}, \epsilon_{i}, \digamma_{i}^{R}\right), a_{R}$ shall solve:

$$
V^{R}\left(S_{i}, x_{i}, l_{i}, \epsilon_{i}, \digamma_{i}^{R}\right)=\max _{j}\left\{p_{j}^{R}\left(S_{i} \mid \digamma_{i}^{R}\right) v_{i j}+\left(1-p_{j}^{R}\left(S_{i} \mid \digamma_{i}^{R}\right)\right) v_{i 0}\right\} .
$$

In general, given $V^{r+1}\left(S_{i}, x_{i}, l_{i}, \epsilon_{i}, \cdot\right)$ and the state variables $\left(S_{i}, x_{i}, l_{i}, \epsilon_{i}, \digamma_{i}^{r}\right)$, with $V^{R+1}(\cdot)=v_{i 0}$, the continuation value for $i$ at Round $r \leq R$ is given by

$$
V^{r}\left(S_{i}, x_{i}, l_{i}, \epsilon_{i}, \digamma_{i}^{r}\right)=\max _{j \in J}\left\{p_{j}^{r}\left(S_{i} \mid \digamma_{i}^{r}\right) v_{i j}+\left(1-p_{j}^{r}\left(S_{i} \mid \digamma_{i}^{r}\right)\right) V^{r+1}\left(S_{i}, x_{i}, l_{i}, \epsilon_{i}, \digamma_{i}^{r+1}\right)\right\}
$$

The process continues until $r=1$, where $a_{1}$ solves:

$$
V^{1}\left(S_{i}, x_{i}, l_{i}, \epsilon_{i}, \digamma_{i}^{1}\right)=\max _{j}\left\{p_{j}^{1}\left(S_{i} \mid \digamma_{i}^{1}\right) v_{i j}+\left(1-p_{j}^{1}\left(S_{i} \mid \digamma_{i}^{1}\right)\right) V^{2}\left(S_{i}, x_{i}, l_{i}, \epsilon_{i}, \digamma_{i}^{2}\right)\right\} .
$$

The backward induction process above constructs an optimal list $\left(a_{1}, \ldots, a_{R}\right)$.

We show the contents of $F_{i}^{r}$ and the determination of $p_{j}^{r}(\cdot)$, using as examples, the standard BM and the BM used in Barcelona, the latter being a special and more complicated case of the former. ${ }^{29}$

Case 1) School-Specific Priorities and a Single Lottery Number (Standard BM) When a household has a single lottery number across all tie-breaking cases, correlation arises between admissions probabilities across rounds. Losing the lottery for $a_{r}$ reveals that one's lottery number is below $c u t_{a_{r}}$. Therefore, the probability of being allocated in Round $r+1$ conditional on being rejected by $a_{r}$ is (weakly)

\footnotetext{
${ }^{29}$ The easiest case happens when applicants are given i.i.d. school-specific lottery numbers, under which $V^{r}\left(\cdot, \digamma_{i}^{r}\right)=V^{r}(\cdot)$ and the constraint for $(7)$ is

$$
p_{j}^{r}\left(S_{i} \mid \digamma_{i}^{r}\right)=p_{j}^{r}\left(S_{i}\right)=\left\{\begin{array}{l}
1 \text { if } r<\bar{r}_{j} \text { or }\left(r=\bar{r}_{j} \text { and } s_{i j}>\bar{s}_{j}\right), \\
1-c u t_{j} \text { if } r=\bar{r}_{j} \text { and } s_{i j}=\bar{s}_{j}, \\
0 \text { otherwise. }
\end{array}\right.
$$
}


lower than the unconditional probability. Let $\bar{\xi}_{i}^{r} \in[0,1]$ be the upper bound of one's random number conditional on one's rejection history $\left(\bar{\xi}_{i}^{1}=1\right)$. All relevant information reduces to $\bar{\xi}_{i}^{r}$, i.e., $\digamma_{i}^{r}=\bar{\xi}_{i}^{r}$. Constraints for $(7)$ are

$$
\begin{aligned}
& \bar{\xi}_{i}^{r+1}=\left\{\begin{array}{l}
\min \left\{c u t_{j}, \bar{\xi}_{i}^{r}\right\} \text { if } s_{i j}=\bar{s}_{j} \text { and } r=\bar{r}_{j}, \\
\bar{\xi}_{i}^{r} \text { otherwise, }
\end{array}\right. \\
& p_{j}^{r}\left(S_{i} \mid \bar{\xi}_{i}^{r}\right)=\left\{\begin{array}{l}
1 \text { if } r<\bar{r}_{j} \text { or }\left(r=\bar{r}_{j} \text { and } s_{i j}>\bar{s}_{j}\right), \\
\max \left\{0, \frac{\bar{\xi}_{i}^{r}-c u t_{j}}{\bar{\xi}_{i}^{r}}\right\} \text { if } r=\bar{r}_{j} \text { and } s_{i j}=\bar{s}_{j}, \\
0 \text { otherwise. }
\end{array}\right.
\end{aligned}
$$

Condition (8) is the updating rule: $\bar{\xi}_{i}^{r+1}$ will decrease to $\min \left\{c u t_{j}, \bar{\xi}_{i}^{r}\right\}$ if $i$ is in the tied priority group and loses the lottery. ${ }^{30}$ The second equality in (9) follows the uniform distribution with truncated support $\left[0, \bar{\xi}_{i}^{r}\right]$.

Case 2) Constant Priority and a Single Lottery Number (Barcelona) The priority score of one's top-listed school carries over to future rounds. As a result, the continuation values for $r>1$ depend on the top-listed school $\left(a_{1}\right)$; and $S_{i}$ in $(7)$ now becomes a vector of identical elements, $s_{i a_{1}} \mathbf{1} \equiv\left[s_{i a_{1}}, \ldots, s_{i a_{1}}\right]$. With $s_{i a_{1}} \mathbf{1}$ being the priority score vector, the problem for $r>1$ remains the same as in Case 1). For Round 1, one solves the following problem $V^{1}\left(S_{i}, x_{i}, l_{i}, \epsilon_{i}, \bar{\xi}_{i}^{1}=1\right)=$

$$
\max _{j \in J}\left\{p_{j}^{1}\left(s_{i j} \mathbf{1} \mid 1\right) v_{i j}+\left(1-p_{j}^{1}\left(s_{i j} \mathbf{1} \mid 1\right)\right) V^{2}\left(s_{i j} \mathbf{1}, x_{i}, l_{i}, \epsilon_{i}, \bar{\xi}_{i}^{2}\right)\right\}
$$

s.t. Conditions (8), (9) .

That is, the choice in Round 1 governs the vector of priority scores.

Remark 2 Multiple lists may yield the same value. Let $\mathbf{A}^{1}\left(x_{i}, l_{i}, \epsilon_{i}\right)$ be the set of optimal lists for a strategic household. All lists in the optimal set, including the one derived by backward induction, are identical up to the payoff-relevant part of the lists and imply the same allocation outcome. ${ }^{31}$

\footnotetext{
${ }^{30}$ Going to Round $r+1$ means one must have been rejected in Round $r$.

${ }^{31}$ For example, consider a list $A^{1}=\left\{a_{1}^{1}, \ldots, a_{r}^{1}, \ldots a_{R}^{1}\right\}$, by the specification of $\left\{u_{i j}\right\}$, each $a_{r}^{1}$ is generically unique if no school listed before it has a $100 \%$ admissions rate for the household. However, if for some $r<R$, the admissions rate for the $r^{t h}$ listed school is one, then any list that shares the same first $r$ ordered elements is also optimal. See the online appendix for other cases.
} 


\section{Estimation}

\subsection{Further Empirical Specification}

As described in detail in Appendix A1, the utility function takes the following form

$$
\begin{aligned}
U\left(w_{j}, x_{i}, d_{i j}, \zeta_{j}\right)= & \left.\tau_{1} I \text { (single parent }\right)+\tau_{2}\left(\operatorname{sib}_{i j}-\operatorname{sib}_{i 0}\right)-C\left(d_{i j}\right) \\
& +\sum_{e=1}^{3}\left(\delta_{0 e}+\delta_{1 e} \zeta_{j}+w_{j} \alpha_{e}\right) I\left(e d u_{i}=e\right) .
\end{aligned}
$$

In particular, $\tau_{2}$ is added to $i$ 's evaluation of $j$ if a sibling is enrolled in $j$, subtracted from $i$ 's evaluation of all schools if a sibling is in the outside option ( $\left.\operatorname{sib}_{i 0}=1\right) . C\left(d_{i j}\right)$ is a distance cost function. The second line of (11) specifies the part of the utility that varies across households with different education levels.

With potential correlation between school characteristics that are unobserved $\left(\zeta_{j}\right)$ and observed $\left(w_{j}\right)$, estimates of $\alpha$ in (11) may be inconsistent. Yet, one can combine the effects of $\left(w_{j}, \zeta_{j}\right)$ and rewrite the second line of (11) as

$$
\sum_{e}\left(\delta_{0 e}+\delta_{1 e} \kappa_{j}+w_{j} \rho_{e}\right) I\left(e d u_{i}=e\right)
$$

The reduced-form parameters $\rho$ and $\left\{\kappa_{j}\right\}_{j}$ can be consistently estimated; and each of them is some combination of structural parameters $\alpha, \delta$ and $\zeta$. For the goal of this paper, it is sufficient to estimate $\rho$ and $\left\{\kappa_{j}\right\}_{j}$ instead of $\alpha$ and $\zeta{ }^{32}$

\subsection{The Likelihood}

Let parameter vector $\Theta \equiv\left[\Theta_{u}, \Theta_{T}\right]$, where $\Theta_{u}$ governs household preferences, and $\Theta_{T}$ governs type distribution. Let $O_{i} \equiv\left[\widetilde{A}_{i}, \widetilde{e}_{i} \mid \widetilde{j}_{i}\right]$ be the observed outcomes for household $i$, where $\widetilde{A}_{i}$ is the application list, $\widetilde{j}_{i}$ is the assigned school, and $\widetilde{e}_{i}$ is enrollment. Conditional on being type $T$, the probability of observing $O_{i}$ is given by

$$
L_{i}^{T}\left(\Theta_{u}\right)=\int\left\{\begin{array}{l}
I\left(\widetilde{A}_{i} \in \mathbf{A}^{T}\left(x_{i}, l_{i}, \epsilon_{i} ; \Theta_{u}\right)\right) \times \\
{\left[\widetilde{e}_{i} \Phi\left(\frac{\bar{u}_{i \tilde{j}}\left(\Theta_{u}\right)+\epsilon_{i \widetilde{j}_{i}}}{\sigma_{\eta}}\right)+\left(1-\widetilde{e}_{i}\right)\left(1-\Phi\left(\frac{\bar{u}_{i \tilde{j}_{j}}\left(\Theta_{u}\right)+\epsilon_{i \tilde{j}_{i}}}{\sigma_{\eta}}\right)\right)\right]}
\end{array}\right\} d F_{\epsilon}\left(\epsilon ; \sigma_{\epsilon}\right),
$$

\footnotetext{
$32(11)$ and (12) are invariant to our counterfactual policy changes.
} 
where $\mathbf{A}^{T}(\cdot)$ is the set of model-predicted optimal application lists for a type- $T$ household, and $\Phi\left(\frac{\bar{u}_{\tilde{j} \tilde{j}}\left(\Theta_{u}\right)+\epsilon_{i \tilde{j}_{i}}}{\sigma_{\eta}}\right)$ is the probability that this household will enroll in $\widetilde{j}_{i}$. Integrating over the type distribution, $i$ 's contribution to the likelihood is

$$
L_{i}(\Theta)=\lambda\left(x_{i}, l_{i} ; \Theta_{T}\right) L_{i}^{1}\left(\Theta_{u}\right)+\left(1-\lambda\left(x_{i}, l_{i} ; \Theta_{T}\right)\right) L_{i}^{0}\left(\Theta_{u}\right)
$$

The log likelihood of the whole sample is given by $\mathbf{L}(\Theta)=\sum_{i} \ln \left(L_{i}(\Theta)\right)$.

\subsection{Identification}

We give an overview of the identification in this subsection and leave the formal proof in the online appendix. The identification relies on the following assumptions.

A1: There does not exist a vector of household observables $x$ and a school $j$, such that all households with $x$ have probability zero of being admitted to school $j$.

A2: Household tastes $\epsilon$ are drawn from an i.i.d. unimodal distribution, with mean normalized to zero; and they are independent of school characteristics, household observables $(x, l)$ and household type $(T)$.

A3: At least one continuous variable in the utility function is excluded from the type distribution. Conditional on variables that enter the type distribution function, the excluded variable is independent of household type $T$.

To illustrate the identification challenge, consider a situation where each household only applies to one school, which is a less favorable situation for identification because we would have less information, and suppose there is no post-application shock. ${ }^{33}$ If all households are non-strategic, the model boils down to a multinomial discrete choice model with a household choosing the highest $\bar{u}_{i j}\left(\Theta_{u}\right)+\epsilon_{i j}$. The identification of such models is well-established under very general conditions (e.g., Matzkin (1993)). If all households are strategic, a household considers the admissions probabilities $\left\{p_{i j}\right\}_{j}$ and chooses the option with the highest expected value. ${ }^{34}$ With the admissions probabilities observed from the data, this model is identified with A1. ${ }^{35}$ The challenge exists because we allow for a mixture of both types of households. In the following,

\footnotetext{
${ }^{33}$ The post-application shock is identified from the observed allocation and enrollment outcomes.

${ }^{34}$ Agarwal and Somaini (2016) show conditions under which one can nonparametrically identify household preferences when all of them are strategic.

${ }^{35}$ If for all households with $x$, the admissions probabilities to $j$ are zero, the utility for school $j$ for these households is unidentifiable, because the expected value of applying to $j$ is zero regardless of the level of utility.
} 
we first explain A2-A3, then give the intuition underlying the identification proof.

\subsubsection{A2 and A3 in Our Framework}

We observe application lists with different distance-quality-risk combinations with different frequencies in the data. The model predicts that households of the same type tend to make similar application lists. Given A2, the distributions of typerelated variables will differ around the modes of the observed choices, which informs us of the correlation between type $T$ and these variables. A3 guarantees that different behaviors can arise from exogenous variations within a type. To satisfy A3, we need to make some restrictions on how household observables $\left(x_{i}, l_{i}\right)$ enter type distribution and utility. Conditional on distance, a non-strategic household may not care too much about living to the left or the right of a school, but a strategic household may be more likely to have chosen a particular side so as to take advantage of the priority zone structure. ${ }^{36}$ However, given that households, strategic or not, share the same preferences about school characteristics and distances, there is no particular reason to believe that everything else being equal, the strategic type will live closer to a particular school than the non-strategic type would just for pure distance concerns. ${ }^{37}$ In other words, because the only difference between a strategic type and a nonstrategic type is whether or not one considers the admissions probabilities, which are affected by one's home location only via the zone to which it belongs to, we assume that home location $l_{i}$ enters the type distribution only via the school zone $z_{l_{i}}$, i.e., $\lambda\left(x_{i}, l_{i}\right)=\lambda\left(x_{i}, z_{l_{i}}\right)$. In contrast, household utility depends directly on the homeschool distance vector $d_{i}$. Conditional on being in the same school zone, households with similar characteristics $x$ but different home addresses still face different homeschool distance vectors $d$, as required in A3.

\subsubsection{The Intuition for Identification}

The data contains rich information for identification. First, one can compare a household's listed schools with other schools. Due to unobserved school characteristics, some seemingly good schools may in fact be unattractive, making it not as popular as

\footnotetext{
${ }^{36}$ Without directly modeling households' location choices, we allow household types to be correlated with the characteristics of the school zones they live in. We leave the incorporation of household location choices for future extensions.

${ }^{37}$ See the online appendix for evidence from the data supporting this assumption.
} 
it "should have been" among most households. Controlling for such common factors, as we do in the model, a household may still leave out some seemingly good schools due to unobserved tastes. A2 implies that tastes are independent of household-schoolspecific admissions probabilities, which should not lead to a systematic relationship between a school being listed and a household's chances of getting into this school. However, as will be shown in Section 5, for a large fraction of households, when they left out schools better than their listed ones in terms of quality, fees and distance, in most cases, these better schools were ones for which they had lower chances. Such behavior is highly consistent with strategizing instead of truth-telling.

Second, one can explore the fact that admissions probabilities increase discontinuously with in-zone status. Most illustratively, consider households along the border of two zones. Were all households non-strategic, applications should be very similar among households along both sides of the border. In contrast, were most households strategic, applications would be very different across the border.

Finally, conditional on $\left(x, z_{l}\right)$, the variation in $d$ induces different behaviors within the same type; and conditional on $\left(x, z_{l}, d\right)$, different types behave differently. In particular, although households share the same preference parameters, different types of households will behave as if they have different sensitivities to distance. For example, consider households with the same $\left(x, z_{l}\right)$ and a good school $j$ out of their zone $z_{l}$. As the distance to $j$ decreases along household addresses, more and more non-strategic households will apply to $j$ because of the decreasing distance cost. However, the reactions will be much less obvious among the strategic households, because they take into account the risk of being rejected, which remains unchanged no matter how close $j$ is as long as it is out of $z_{l}$. The different distance-elasticities among households therefore inform us of the type distribution within $\left(x, z_{l}\right)$. This identification argument does not depend on specific parametric assumptions. For example, Lewbel (2000) shows that similar models are semiparametrically identified when an A3-like excluded variable with a large support exists. However, to make the exercise feasible, we have made parametric assumptions. ${ }^{38}$

\footnotetext{
${ }^{38}$ We have to use parametric assumptions because semiparametric estimation is empirically infeasible, and because the support of $d$ is bounded by the size of the city, which is not large enough relative to the (unbounded) support of household tastes, as required in Lewbel (2000).
} 


\subsubsection{Obviously Non-Strategic Households}

The identification of our model is further facilitated by the fact that we can partly observe household type directly from the data: there is one particular type of "mistakes" that a strategic household will never make, which is a sufficient (but not necessary) condition to spot a non-strategic household. ${ }^{39}$ Intuitively, if a household's admissions status is still uncertain for all schools listed so far, and there is another school $j$ it desires, one should never waste the current slot listing a zero-probability school instead of $j$ because the admissions probabilities decrease over rounds. ${ }^{40}$ The idea is formalized in the following claim and proved in the online appendix. ${ }^{41}$

Claim 1 An application list with the following features is sufficient but not necessary evidence that the household must be non-strategic: 1) for some $r^{\text {th }}$ element $a_{r}$ on the list, the household faces zero admissions probability at the $r^{\text {th }}$ round, and 2) it faces admissions probabilities lower than 1 for all schools listed in previous rounds, and 3) it faces a positive but lower than $100 \%$ admissions probability for the school listed in a later slot $r^{\prime} \geq r+1$ and no school listed between $a_{r}$ and $a_{r^{\prime}}$ admits the household with probability 1.

\section{Data}

We focus on applications among families with children that turned 3 years old in 2006 or 2007 and lived in Barcelona. For each applicant, we observe the application list, the assignment and enrollment outcomes, home address, family background, and the ID of the school(s) her siblings were enrolled in the year of her application. For each school, we observe its type (public or semi-public), a measure of quality, capacity and service fees. The online appendix describes our data sources.

\footnotetext{
${ }^{39}$ If the support of household characteristics is full conditional on being obviously non-strategic, household preferences can be identified using this subset of households without A1, since $\epsilon$ is independent of $(x, l)$. However, our identification does not rely on the existence of obviously non-strategic households.

${ }^{40}$ For example, consider an application list $(1,2,3, \ldots)$ by Household $i$ with $S_{i}$, where School 1 is filled up in Round 1 with $p_{1}^{1}\left(S_{i}, \cdot\right)<1$, School 2 is filled up in Round 1 hence $p_{2}^{2}(\cdot)=0$, and School 3 is filled up in Round 3 and $0<p_{3}^{3}\left(S_{i}, \cdot\right)<1$. This list is irrational, because one has probability 1 of getting into School 3 in Round 2 and hence is strictly better off with any list starting with $(1,3)$ instead of $(1,2)$.

${ }^{41}$ Abdulkadiroğlu et al. (2006) use a mistake similar to Feature 1) in Claim 1 to spot non-strategic households, which is to list a school over-demanded in the first round as one's second choice.
} 


\subsection{Admissions Thresholds}

Assuming each household is a small player that takes the admissions thresholds as given, we can recover all parameters by estimating an individual decision model. Given the observed applications and the priority rules, we make 1,000 copies for each observed application list, involving all participating households (11,871 in 2006), and assign each copy a random lottery number. We simulate the assignment results in this enlarged market to obtain $\left\{\left(\bar{r}_{j}, \bar{s}_{j}, c u t_{j}\right)\right\}_{j}$, which are treated as the ones households expected when they applied. ${ }^{42}$

\subsection{Summary Statistics}

For estimation, we drop 3,152 observations (obs) whose locations cannot be matched in the GIS (geographic information system) ${ }^{43} 31$ obs whose outcomes were inconsistent with the official rule, 191 obs with special-need children or post-dealine (and hence ineligible) applications, and those with missing information. ${ }^{44}$ The final estimation sample has 6,836 obs. Table 1 summarizes school characteristics. ${ }^{45}$ Compared to public schools, semi-public schools have higher quality and larger capacities. Table 2 reports household characteristics in the estimation sample. ${ }^{46}$ Households had priority for 22 schools on average but with considerable dispersions depending on their zones.

Table 1 School Characteristics

\begin{tabular}{lrrr}
\hline \hline & Public & Semi-Public & All \\
Quality & $7.4(0.8)$ & $8.0(0.5)$ & $7.7(0.7)$ \\
Fees (100 Euros) & 0 & $12.8(5.7)$ & $6.4(7.5)$ \\
\# Classes & $1.4(0.5)$ & $1.8(1.0)$ & $1.6(0.8)$ \\
Observations & 158 & 159 & 317 \\
\hline
\end{tabular}

\footnotetext{
${ }^{42}$ Agarwal and Somaini (2016) prove consistency of the obtained admissions probabilities for the class of mechanisms under consideration.

${ }^{43}$ We know their priority scores and applications, which enables us to include them in the calculation of admissions thresholds.

${ }^{44}$ In the estimation, we exclude 748 parents who reported their education as "high school or above." In policy simulations, we include this subsample so as to make equilibrium assignments. We estimate the probability of each of them as being college educated as a flexible function of all the other observable characteristics, by comparing them with those who reported exactly high-school or college education. The model fit for this subsample is as good as that for the estimation sample, available on request.

${ }^{45}$ School quality is measured by average student test scores on a scale from 0 to 10 .

${ }^{46}$ Following the literature on child development, we use mother's education as the definition of parental education if the mother is present in the household, otherwise, we use the father's education.
} 
Table 2 Household Characteristics

\begin{tabular}{lc}
\hline \hline Parental Edu $^{a}<\mathrm{HS}$ & $29.8 \%$ \\
Parental Edu $=$ HS & $30.4 \%$ \\
Parental Edu $>$ HS & $39.8 \%$ \\
Single Parent & $15.8 \%$ \\
Have school-age older sibling(s) & $42.2 \%$ \\
\# Schools in Zone & $22.3(7.9)$ \\
Average school quality in zone & $7.8(0.3)$ \\
Observations & 6,836 \\
\hline
\end{tabular}

${ }^{a}$ Parental Edu: mother's edu if she is present, otherwise father's edu.

The left panel of Table 3 shows that most of households listed no more than 3 schools, with $47 \%$ listing only one school. High-school-educated (HS) parents and single parents tended to list more schools than others. The right panel of Table 3 shows the round at which households were assigned. In equilibrium, most households $(93 \%)$ were assigned to their first choices. However, this does not imply low risk. ${ }^{47}$ Among those assigned to their first choices, the average admissions probability was $94.6 \%$, with the lowest being 0.2 . Of all schools, $44 \%$ were filled up in Round 1, while $40 \%$ were leftovers. That is, households face very high stakes: a large number of schools were over-demanded; and once rejected in Round 1, most schools one could get into were leftovers. The fact that most households were assigned to their first choices suggests both the prevalence of strategic play and a large amount of coordination in equilibrium. Table 4 summarizes the characteristics of top-listed schools: school quality, distance and fees all increase with parental education. Table 5 shows that $97 \%$ of all students were enrolled in the public school system. Among those assigned to their first choice, $2.2 \%$ chose not to enroll, which can be rationalized by ex-post shocks. $^{48}$

\footnotetext{
${ }^{47}$ Other studies also find that most households were assigned to their first choices under manipulable mechanisms, e.g., Abdulkadiroğlu et al. (2006), Hastings et al. (2009), Lavy (2010) and Agarwal and Somaini (2016).

${ }^{48}$ The online appendix shows that the probabilities of being assigned in Round 1 were lower for non-enrollees, suggesting that households who took higher risks might have better outside options.
} 
Table 3 Number of Schools Listed and Assignment (\%)

\begin{tabular}{lcccc|cccc}
\hline \hline & \multicolumn{4}{c|}{ Number of Schools Listed } & \multicolumn{4}{c}{ Assignment Round } \\
& 1 & 2 & 3 & 4 or more & 1st & 2nd & 3rd-10th & Unassigned \\
All & 46.9 & 12.4 & 16.9 & 23.8 & 93.0 & 2.8 & 1.5 & 2.7 \\
Parental Edu $<$ HS & 49.8 & 15.0 & 19.5 & 15.7 & 93.2 & 2.7 & 1.6 & 2.5 \\
Parental Edu = HS & 43.4 & 12.1 & 18.4 & 26.2 & 92.0 & 3.5 & 1.5 & 3.0 \\
Parental Edu $>$ HS & 47.4 & 10.6 & 13.9 & 20.1 & 93.7 & 2.3 & 1.3 & 2.7 \\
Single-Parent & 43.3 & 14.7 & 16.8 & 25.2 & 94.0 & 1.9 & 1.4 & 2.7 \\
\hline
\end{tabular}

Table 4 Top-Listed Schools

\begin{tabular}{lccc}
\hline \hline & Quality & Distance (100m) & Fees (100Euros) \\
All & $7.9(0.6)$ & $7.1(8.7)$ & $8.1(7.7)$ \\
Parental Edu < HS & $7.6(0.7)$ & $5.2(6.2)$ & $5.4(6.6)$ \\
Parental Edu = HS & $7.9(0.5)$ & $7.0(8.6)$ & $8.1(7.5)$ \\
Parental Edu $>$ HS & $8.2(0.4)$ & $8.7(9.9)$ & $9.9(8.1)$ \\
Single-Parent & $8.0(0.6)$ & $8.1(9.9)$ & $8.6(8.4)$ \\
\hline
\end{tabular}

For suggestive evidence of strategic behavior, Table 6 compares a household's toplisted school with other schools. A school is labeled as "better in 3" if it had higher quality, lower tuition and shorter distance than one's top-listed school; as "better in 2" if it failed one of the three conditions. Of all households, $41 \%$ had at least one "better in 3" school, with the average number being 5.2. Almost all households had a considerable number of "better in 2" schools. Of course, unobservable tastes and/or school characteristics may drive these choices, both of which are incorporated in our model. However, these unobservables are unlikely to suffice. First, "better" schools overlap very little across households, suggesting a very limited role by school unobservables. Second, these "better" schools were disproportionally unlikely to be schools for which the household had higher admissions probabilities. For example, for an average household with some "better in 3" schools, for only $14 \%$ of such schools did the household have higher chances than its top choice. The same pattern holds if we exclude those who top-listed a sibling school. These facts are hard to rationalize with truthful reporting, unless households' unobserved tastes vary systematically with the household-specific admissions probabilities. ${ }^{49}$ These data facts provide information for the identification of household type and preference distribution.

\footnotetext{
${ }^{49}$ The online appendix shows further evidence via regression analyses.
} 
Table 5 Enrollment in Public System (\%)

\begin{tabular}{ll}
\hline \hline All & 96.7 \\
Parental Edu $<$ HS & 97.0 \\
Parental Edu = HS & 97.1 \\
Parental Edu > HS & 96.3 \\
Single-Parent & 96.1 \\
Assigned in Round 1 & 97.8 \\
\hline
\end{tabular}

Table 6 "Better" Schools than the Top-Listed One

\begin{tabular}{lccc}
\hline \hline & \% Households & \# Better Sch & \%Better w/ Higher $p$ \\
All Households (6,836) & & & \\
Have Sch. Better in 3 Aspects & $40.7 \%$ & $5.2(9.9)$ & $14.1 \%$ \\
Have Sch. Better in 2 Aspects & $99.8 \%$ & $75.9(45.1)$ & $10.5 \%$ \\
Sib Sch. not Top-listed (4,025) & & & \\
Have Sch. Better in 3 Aspects & $39.3 \%$ & $4.6(8.7)$ & $24.8 \%$ \\
Have Sch. Better in 2 Aspects & $99.8 \%$ & $77.3(44.2)$ & $17.8 \%$ \\
\hline
\end{tabular}

$\%$ Households: \% of households that satisfy the condition specified in each row.

\#Better Sch: average (std.dev.) num. of better schools for households with such schools.

\%Better w/ higher $p$ : \% of better sch with higher admission prob. than one's top choice.

\section{Results}

\subsection{Parameter Estimates}

Table 7 presents the estimated parameters governing household preferences. The left panel reports structural parameters governing parts of the utility function that vary within an education group and the dispersions of tastes $\left(\sigma_{\epsilon}\right)$ and post-application shocks $\left(\sigma_{\eta}\right)$. The cost of distance is convex, although the square term is not precisely estimated. $^{50}$ We also allow for two jumps in the cost of distance. The first jump is set at 500 meters, an easy-to-walk distance even for a 3-year old; the second is at 1 kilometer, a long yet manageable walking distance. As households may have to use other transportation methods beyond these distances, the cost of distance jumps significantly at the thresholds. The parameter on sibling schools adjusts such that

\footnotetext{
${ }^{50} \mathrm{As}$ in other discrete choice models, we need to normalize one coefficient in the utility function in order to identify $\sigma_{\epsilon}$ and $\sigma_{\eta}$; and we normalize the linear term on distance to -1 .
} 
most $(97 \%)$ households with sibling schools top-listed them. We find a high $\sigma_{\eta}$, which explains why a household would give up its assigned school, especially if it is its first choice. ${ }^{51}$ Taste dispersion $\sigma_{\epsilon}$ is relatively small, which is consistent with households' low willingness to take risks (Table 6 ).

Table 7 Preference Parameters

\begin{tabular}{|c|c|c|c|c|c|}
\hline \multicolumn{2}{|c|}{ Structural Parameter Estimates $^{a}$} & \multicolumn{4}{|c|}{ Summarize School FE ${ }^{b}$} \\
\hline & & & $\mathrm{Edu}<\mathrm{HS}$ & $\mathrm{Edu}=\mathrm{HS}$ & $\mathrm{Edu}>\mathrm{HS}$ \\
\hline Distance $^{2}$ & $-0.05(0.04)$ & Constant & 2766.3 & 2783.3 & 2423.0 \\
\hline Distance $>5(100 \mathrm{~m})$ & $-55.3(7.1)$ & Quality & 152.0 & 176.4 & 187.8 \\
\hline Distance $>10(100 \mathrm{~m})$ & $-46.5(7.9)$ & Fee & -1.0 & -0.6 & -0.3 \\
\hline Sibling School & $1339.0(86.5)$ & Semi-Public & -0.6 & 6.5 & 0.8 \\
\hline Single Parent & $-404.3(12.2)$ & Capacity & & 0.7 & \\
\hline$\sigma_{\epsilon}($ taste dispersion $)$ & $66.3(6.2)$ & Capacity $^{2}$ & & -0.001 & \\
\hline$\sigma_{\eta}($ post-app shock $)$ & $1937.8(18.7)$ & Quality $^{2}$ & & -9.9 & \\
\hline
\end{tabular}

${ }^{a}$ Structural preference parameter estimates, (standard errors in parentheses).

${ }^{b}$ OLS regression of the estimated school value parameters on observables.

It would be non-informative to report the over 300 parameter estimates $\left(\kappa_{j}\right)$ of school values. Instead, we use an OLS regression of these estimates on observables as a summary (the right panel of Table 7). ${ }^{52}$ These OLS estimates will be unbiased only if the unobserved school characteristics are uncorrelated with the observables. This potential correlation does not affect our policy analyses, which use the consistentlyestimated school values. However, one should be cautious when relating school values and utils to $w_{j}$. With caution, we have the following findings that are consistent with data facts in Tables 3 to 5 . 1) HS parents value schools more than the others, especially the college group, for whom the outside option may be more affordable. 2) Higher educated parents value school quality more and are less sensitive to fees. ${ }^{53} 3$ ) Households prefer schools with larger capacity, which tend to have more resources.

\footnotetext{
${ }^{51}$ The ex-ante value of the outside option is normalized to zero, while the average value of schools $\left(\kappa_{j}\right)$ is estimated to be 3,391 .

${ }^{52}$ The form of the OLS follows model specifications in Section 4.1.2 and Appendix A.

${ }^{53}$ Preferences for quality peak beyond the maximum school quality for the high education group, at 99th percentile for the middle education group, and around 60th percentile for the low group. Other studies also find that parents of different education value school characteristics differently, e.g., Burgess et al. (2009), Hastings et al. (2008), He (2012) and Abdulkadiroğlu et al. (2014).
} 
4) Everything else being equal, semi-public schools are more preferable except for the low-educated group.

Table 8 Type Distribution

\begin{tabular}{lc}
\hline \hline Constant & $-18.9(2.3)$ \\
Single Parent & $0.3(0.5)$ \\
Education $<$ HS & $-0.1(0.2)$ \\
Education $>$ HS & $0.7(0.3)$ \\
No. schools in zone & $-0.1(0.2)$ \\
Average school quality in zone & $3.1(1.1)$ \\
Have an older sibling & $49.0(24.7)$ \\
\hline
\end{tabular}

Table 9 Strategic vs. Non-Strategic Type: Simulation

\begin{tabular}{lcccc}
\hline \hline & Strategic (\%) & \multicolumn{2}{c}{ Strategic } & Non-Strategic \\
All & 96.3 & Schools in zone & \\
Parental Edu < HS & 94.7 & No. Schools & 22.3 & 21.8 \\
Parental Edu = HS & 95.8 & Ave. quality & 7.9 & 7.7 \\
Parental Edu > HS & 97.8 & & & \\
Single-Parent & 96.6 & & & \\
Have an older sibling & 97.1 & & & \\
\hline
\end{tabular}

Table 8 presents the estimated type distribution parameters. Single parents and parents with higher education levels are more likely to be strategic. Although strategic households are not more likely to live in zones with more schools, they are more likely to live in zones with better schools. ${ }^{54}$ Households with older children and therefore have already gone through the process before, are more likely to be strategic. ${ }^{55}$ Based on these estimates, Table 9 shows the simulated type distribution in our sample. Consistent with data facts such as those in Table 6, 96\% of households were strategic; and the fraction increases with education. ${ }^{56}$ To obtain further insights on our findings,

\footnotetext{
${ }^{54}$ We allow for the correlation between zone characteristics and types. The estimates are consistent with our intuition that strategic households may choose home locations to utilize the residence-based priority structure.

${ }^{55}$ One extension is to incorporate the dynamic considerations by households with multiple children.

${ }^{56}$ We find a much smaller fraction of non-strategic households than Abdulkadiroğlu et al. (2006). The main reason is our incorporation of the outside option and the leftover schools, which rationalizes the choices by a substantial fraction of households that might be categorized as non-strategic otherwise. Another reason is the long history of BM in Barcelona, where parents have become very familiar with the mechanism.
} 
we have re-estimated our model with the restriction that only $80 \%$ of households were strategic. The fit of this restricted model is significantly worse, as shown in the online appendix.

\subsection{Model Fits and Out-of-Sample Validation}

The 2007 re-definition of priority zones abruptly changed the school-household-specific priorities: priority schools became those that surrounded each home location. ${ }^{57} \mathrm{We}$ show model fits for both the 2006 and the 2007 samples. ${ }^{58}$ To simulate the 2007 outcomes, we first calculate the admissions probabilities in 2007 via the same procedure as we do for 2006. Then we use the 2007 sample to conduct an out-of-sample validation. ${ }^{59}$ Because the reform came as a surprise and households were unlikely to relocate before submitting their applications in 2007, we simulate the distribution of 2007 household types using the characteristics of their residential zones according to the 2006 definition. ${ }^{60}$

Considered as the most informative test of the model, the first two rows of Table 10 explore the changes in the definition of priority zones. The reform led to situations where some schools were in the priority zone for a household in one year but not in the other, which would affect the behavior of a strategic household. In 2006, $24 \%$ of households top-listed a school that was in their priority zone by the 2006 definition but not by the 2007 definition. In 2007, the fraction of households top-listing these schools dropped to $12 \%$. On the other hand, the fraction of households that top-listed schools in their priority zone only by the 2007 definition but not by the 2006 definition increased from $3 \%$ to $12 \%$ over the two years. The model is able to replicate such behaviors and predicts the changes as being from $24 \%$ to $14.6 \%$ for the first case, and from $4.5 \%$ to $11 \%$ for the second case. The model also replicates the fact that top-listed schools in 2007 were of similar quality, shorter distance and lower tuition, relative to those in 2006 . The model slightly under-predicts the fraction of households assigned in Round 1 for 2006, but closely replicates the enrollment rate.

\footnotetext{
${ }^{57}$ In 2007 , the average (std) number of schools to which a household had priority became 7.0 (1.5).

${ }^{58}$ More fitness tables are in the appendix.

${ }^{59}$ In 2007, 12,335 Barcelona households participated, 7,437 of whom are selected into our validation sample, using the same selection rule as before.

${ }^{60}$ We also assume that strategic households had rational expectation about admissions probabilities in 2007. As shown below, we can fit the data in both years, suggesting that our assumptions are not unreasonable.
} 
Table 10 Model Fits

\begin{tabular}{lcccc}
\hline \hline & \multicolumn{2}{c}{2006} & \multicolumn{2}{c}{2007} \\
& Data & Model & Data & Model \\
Top-Listed Schools & & & & \\
In Zone 06 Only (\%) & 24.1 & 24.1 & 12.0 & 14.6 \\
In Zone 07 Only (\%) & 3.0 & 4.5 & 12.0 & 10.9 \\
Quality & 7.9 & 7.9 & 7.9 & 7.9 \\
Distance (100m) & 7.1 & 7.2 & 6.6 & 7.0 \\
Fee (100 Euros) & 8.1 & 8.1 & 7.9 & 7.8 \\
Assignment Round (\%) & & & \\
1 & 93.0 & 91.3 & 92.0 & 92.6 \\
2 & 2.8 & 4.0 & 3.1 & 3.6 \\
$\geq 3$ & 1.5 & 0.9 & 1.8 & 0.6 \\
Unassigned & 2.7 & 3.8 & 3.1 & 3.2 \\
Enrollment in the Public System (\%) & & \\
All & 96.7 & 96.5 & 97.6 & 96.6 \\
Assigned in Round 1 & 97.8 & 97.1 & 98.3 & 97.1 \\
\hline
\end{tabular}

\section{BM vs. DA vs. TTC}

Using the estimated model, we compare the baseline BM with DA and TTC. In a different experiment, presented in the appendix, we assess the impacts of the 2007 reform. In both experiments, households' welfare refers to their evaluations of their assignment outcomes relative to their outside options, i.e., $v_{i j} .{ }^{61}$

\subsection{Theoretical Background}

The DA procedure is similar to BM, however, students are only temporarily assigned to schools in each round and one's chance of being finally admitted to a school does not depend on the ranking of the school on her application. TTC creates cycles of trade between individuals in each round. Each individual in a cycle trades off a seat in her highest-priority school for a seat in her announced most preferred school among those with open seats. Whenever such a cycle is formed the allocation is final.

\footnotetext{
${ }^{61}$ All simulations use the school-household-specific priority scores given by (1), following official rules in the relevant year.
} 
Three properties are considered as desirable but cannot hold simultaneously in a mechanism: Pareto efficiency, truth revealing and the elimination of justified envy (aka stability). ${ }^{62}$ BM satisfies none of the properties. DA and TTC, with the standard priority structure, are both truth revealing, which are the cases we consider. ${ }^{63}$ Between the other two conflicting properties, DA eliminates justified envy, while TTC achieves Pareto efficiency. The welfare comparison between BM and its alternatives is ambiguous because of two competing forces. On the one hand, BM can lead to potential misallocations because households hide their true preferences, which is absent in DA and TTC. On the other hand, BM may better "respect" households' cardinal preferences than DA and TTC (Abdulkadiroğlu et al. (2011)). BM-induced household behaviors increase the chance of a "right match" in that a school is matched to households that value it more. Under a truth-revealing mechanism, households who share the same ordinal preferences will rank schools the same way and have the same chance of being allocated to various schools, regardless of who will gain the most from each school. Given that it is theoretically inconclusive, the welfare comparison between these mechanisms becomes an empirical question, one that we answer below.

\subsection{Results}

Under both DA and TTC with the standard priority structure, all households will list their true preferences. ${ }^{64}$ We simulate each household's application list accordingly and assign them using DA and then using TTC, and compare the results with those from the baseline Barcelona case, i.e., BM with constant priority and single lottery number. ${ }^{65}$ We present our results under the more recent (2007) priority zone structure. ${ }^{66}$

Remark 3 We report total household welfare, the distribution of winners and losers among different subgroups of households, as well as the assignment outcomes. Total

\footnotetext{
${ }^{62}$ Stability requires that there be no unmatched student-school pair $(i, j)$ where student $i$ prefers school $j$ to her assignment and she has higher priority at $j$ than some other student who is assigned a seat at school $j$.

${ }^{63}$ For example, one's priority score in Round 1 does not carry over to future rounds.

${ }^{64}$ To simulate DA and TTC, it is sufficient to know household preferences. However, to compare DA or TTC with the baseline, one needs to know the distribution of household strategic types.

${ }^{65}$ All these mechanisms use random lotteries break ties. For a given set of random lottery numbers, we simulate the allocation procedure and obtain the outcomes for all students. We repeat this process many times to obtain the expected (average) outcomes for each simulated student.

${ }^{66}$ The 2006 results are similar.
} 
household welfare is not necessarily the criterion for social welfare, which may involve different weights across households. Given that we can calculate the welfare at the household level, our results can be used to calculate any weighted social welfare. Given a social objective, our results can be easily used for policy-making purposes, although we do not necessarily recommend one mechanism over another in this paper.

\subsubsection{Household Welfare Comparison}

The first column of Table 11 shows household welfare under BM. Average welfare decreases by 5.4 utils or 1,020 euros when BM is replaced by DA. ${ }^{67}$ The impacts differ across households qualitatively and quantitatively, which leads to a wide dispersion. Welfare decreases more for non-strategic households. Although the welfare loss in utils decreases with education, the decreasing price sensitivity across education groups yields a different ranking of euros lost. Clearly, one should not compare the losses directly across education groups because they view the same euro amount differently. ${ }^{68}$ The last two columns of Table 11 compares BM with TTC. For an average household, the change from BM into TTC increases the welfare by 460 euros. As such, TTC leads to the highest total household welfare among all three alternatives. The gains are especially large for the non-strategic households, measured at 1,970 euros.

Result 1: In terms of total household welfare, the three mechanisms are ranked as TTC $>$ BM $>$ DA. There are more losers than winners from a change of BM into DA, and more winners than losers from a change of BM into TTC (Table 12).

\footnotetext{
${ }^{67}$ The translation of utils to euros uses the education-specific coefficients for fees as in Table 7 .

${ }^{68}$ Although the households we study face a much larger choice set and a more complicated problem under BM as a result of the special priority rule in Barcelona, our findings are not peculiar. Hwang (2015) and Agarwal and Somaini (2016), who study BM with standard priority rules, also find that DA would yield lower welfare. Moreover, our finding that DA decreases welfare for both strategic and non-strategic households is consistent with some recent theoretical work, e.g., Abdulkadiroğlu et al. (2011).
} 
Table 11 Household Welfare: BM vs. DA vs. TTC

\begin{tabular}{|c|c|c|c|c|c|c|c|}
\hline \multirow[t]{2}{*}{$\%$} & \multirow[t]{2}{*}{$\mathrm{BM}^{a}$} & \multicolumn{4}{|c|}{$\mathrm{DA}_{-\mathrm{BM}^{b}}$} & \multirow{2}{*}{\multicolumn{2}{|c|}{$\Delta$ utils }} \\
\hline & & \multicolumn{2}{|c|}{$\Delta$ utils } & \multicolumn{2}{|c|}{$\Delta 100$ euros } & & \\
\hline All & $3,811(633)$ & \multicolumn{2}{|c|}{$-5.4(30.9)$} & \multicolumn{2}{|c|}{$-10.2(71.8)$} & \multicolumn{2}{|c|}{$1.9(40.5)$} \\
\hline Strategic & $3,810(633)$ & \multicolumn{2}{|c|}{$-5.3(30.3)$} & \multicolumn{2}{|c|}{$-10.2(69.9)$} & \multicolumn{2}{|c|}{$1.6(39.9)$} \\
\hline Non-strategic & $3,818(629)$ & \multicolumn{2}{|c|}{$-5.7(41.0)$} & \multicolumn{2}{|c|}{$-19.7(131.8)$} & \multicolumn{2}{|c|}{$8.3(51.5)$} \\
\hline $\mathrm{Edu}<\mathrm{HS}$ & $3,690(600)$ & \multicolumn{2}{|c|}{$-9.9(28.3)$} & \multicolumn{2}{|c|}{$-10.0(28.6)$} & \multicolumn{2}{|c|}{$0.1(31.4)$} \\
\hline $\mathrm{Edu}=\mathrm{HS}$ & $3,934(619)$ & \multicolumn{2}{|c|}{$-5.7(33.0)$} & \multicolumn{2}{|c|}{$-18.3(106.3)$} & \multicolumn{2}{|c|}{$2.5(44.1)$} \\
\hline $\mathrm{Edu}>\mathrm{HS}$ & $3,792(647)$ & \multicolumn{2}{|c|}{$-2.1(30.3)$} & \multicolumn{2}{|c|}{$-3.7(54.6)$} & \multicolumn{2}{|c|}{$2.7(42.8)$} \\
\hline \multirow{3}{*}{\multicolumn{8}{|c|}{ 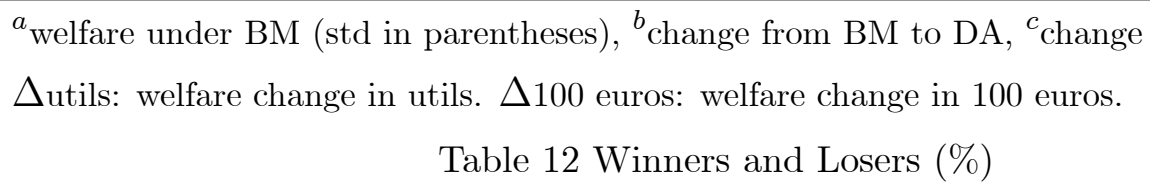 }} \\
\hline & & & & & & & \\
\hline & & & & & & & \\
\hline & & & \multicolumn{2}{|c|}{$\mathrm{BM}$ to DA } & \multicolumn{3}{|c|}{$\mathrm{BM}$ to TTC } \\
\hline & & & Winner & Loser & Winr & her & Loser \\
\hline & All & & 11.7 & 33.0 & 25. & & 21.5 \\
\hline & Strategic & & 11.6 & 32.8 & 24. & & 21.7 \\
\hline & Non-strate & gic & 15.3 & 36.7 & 32. & & 17.5 \\
\hline & $\mathrm{Edu}<\mathrm{HS}$ & & 7.8 & 37.0 & 23. & & 22.1 \\
\hline & $\mathrm{Edu}=\mathrm{HS}$ & & 13.0 & 35.5 & 27. & & 23.0 \\
\hline & $\mathrm{Edu}>\mathrm{HS}$ & & 13.3 & 28.2 & 24. & & 20.0 \\
\hline
\end{tabular}

\subsubsection{Cross-Zone Inequality}

A household's welfare can be significantly affected by the school quality within its zone not only because of the quality-distance trade-off, but also because of the quality-risk trade-off created by the priority structure. For equity concerns, a replacement of BM will be more desirable if it is more likely to benefit those living in poor-quality zones. Table 13 tests whether or not each of the counterfactual reforms meets this goal. In the change from BM to DA, winners live in better zones than losers, which is against the equity goal. The difference in zone quality between these two groups is almost $20 \%$ of a std of quality across all zones. Changing from BM to TTC, the average zone quality is similar across winners and losers.

Result 2: Welfare dependence on zone quality increases with a change from BM to DA, and remains unaffected by a change from BM to TTC. 
Table 13 Zone Quality: Winners vs. Losers

\begin{tabular}{lcccc}
\hline \hline & \multicolumn{2}{c}{ BM to DA } & \multicolumn{2}{c}{ BM to TTC } \\
& Winner & Loser & Winner & Loser \\
All & 7.83 & 7.78 & 7.80 & 7.80 \\
Edu $<$ HS & 7.72 & 7.67 & 7.69 & 7.68 \\
Edu $=$ HS & 7.79 & 7.77 & 7.79 & 7.79 \\
Edu $>$ HS & 7.90 & 7.88 & 7.89 & 7.91 \\
\hline
\end{tabular}

The Cost of the Elimination of Justified Envy Underlying the results in Table 13 is the residence-based priority and the high respect DA has for priorities that enables it to eliminate justified envy. The first three columns of Table 14 show the fraction of households assigned to schools in their own school zones under alternative mechanisms among all households and among those whose favorite schools are out of their zones. The last three columns of Table 14 show households' chances of being assigned to their favorite schools.

Result 3: DA assigns the largest fraction of households to in-zone schools, followed by BM and then TTC. In terms of enabling households to get out of their zones to attend their desired schools, the three mechanisms are ranked as TTC > BM > DA.

Table 14 The Cost of the Elimination of Justified Envy

\begin{tabular}{lcccccc}
\hline \hline & \multicolumn{3}{c}{ Assigned in Zone (\%) } & \multicolumn{3}{c}{ Assigned to Favorite (\%) } \\
& BM & DA & TTC & BM & DA & TTC \\
All Households & 65.1 & 70.1 & 58.4 & 68.3 & 64.1 & 67.8 \\
Favorite is out of Zone & 28.4 & 38.4 & 18.8 & 47.2 & 41.8 & 58.9 \\
\hline
\end{tabular}

Remark 4 Like most studies on school choice mechanisms, our cross-mechanism comparisons takes the priority structure as given. ${ }^{69}$ These structures differ across cities; and they play an essential role. We leave it for future research to understand the trade-offs and social objectives underlying these different priority structures.

\subsubsection{School Assignment}

Table 15 presents changes in the characteristics of schools households are assigned to. When BM is replaced by DA, households are assigned to schools with higher

\footnotetext{
${ }^{69}$ See Kominers and Sönmez (2012) and Dur et al. (2013) for examples of theoretical studies on priority structures.
} 
quality, shorter distance and higher fees. ${ }^{70}$ The low-education group sees the smallest increase in quality and deduction in distance, while the largest increase in fees, which explains why the average welfare (utils) decreases the most for this group (Table 11). When BM is replaced by TTC, households are assigned to schools with higher quality, longer distance and higher fees. That is, BM leads to misallocation as people hide their true preferences, who inefficiently apply for in-zone schools for which they higher priorities, while giving up higher-quality out-of-zone schools.

Result 4: Compared to TTC, both BM and DA inefficiently assign students to schools that are closer but of lower quality.

Table 15 School Assignment

\begin{tabular}{lccc|ccc}
\hline \hline & & \multicolumn{3}{c|}{ DA-BM } & \multicolumn{3}{c}{ TTC-BM } \\
& Quality & Distance(100m) & Fees(euro) & Quality & Distance & Fees \\
All & $0.04(0.4)$ & $-0.4(4.7)$ & $7.8(333.2)$ & $0.05(0.5)$ & $0.6(5.5)$ & $12.4(427.0)$ \\
Edu $<$ HS & $0.02(0.3)$ & $-0.1(4.2)$ & $8.8(284.6)$ & $0.03(0.4)$ & $0.5(4.7)$ & $2.4(360.4)$ \\
Edu = HS & $0.05(0.5)$ & $-0.5(5.1)$ & $6.3(356.0)$ & $0.06(0.5)$ & $0.7(5.9)$ & $17.1(461.1)$ \\
Edu $>$ HS & $0.05(0.5)$ & $-0.5(4.7)$ & $8.3(343.9)$ & $0.06(0.5)$ & $0.7(5.6)$ & $15.3(438.8)$ \\
\hline
\end{tabular}

\section{Conclusion}

We have developed a model of households' choices of schools under the Boston mechanism (BM) and estimated the joint distribution of household preferences and their strategic types, using data before a drastic change in household-school priorities. The estimated model has been validated using data after this drastic change. We have developed an efficient method to fully solve household problems even when the choice set is large. This method is applicable to a broad class of choice mechanisms, which may expand the scope of empirical studies in this literature beyond what has been feasible using the traditional solution method.

We have quantified the welfare impacts of replacing the Boston mechanism with its two alternatives, DA and TTC. A change from BM to DA decreases household welfare and exacerbates inequalities across residential zones. A change from BM to TTC increases welfare but does not affect cross-zone inequalities.

\footnotetext{
${ }^{70} \mathrm{~A}$ non-zero average change in quality is possible because there are more school seats than students city-wise.
} 
The methods developed in this paper and the main empirical findings are promising for future research. One particularly interesting extension is to incorporate household's residential choices into the framework of this paper. Individual households may relocate in order to take advantage of changes in school choice mechanisms and/or in residence-based priority structures. Such individual incentives will in turn affect the housing market. There is a large literature on the capitalization of school quality for housing prices, as reviewed by Black and Machin (2010) and Gibbons and Machin (2008). ${ }^{71}$ An important yet challenging research project involves combining this literature and the framework proposed in our paper, in order to form a more comprehensive view of the equilibrium impacts of school choice mechanisms on households' choices of schools and residential areas, and on the housing market.

\section{References}

Abdulkadiroğlu, A., N. Agarwal and P. Pathak (2014). "The Welfare Effects of Congestion in Uncoordinated Assignment: Evidence from the NYC HS Match," NBER working paper.

Abdulkadiroglu, A., J. Angrist, S. Dynarski, T. Kane, and P. Pathak (2011). "Accountability and Flexibility in Public Schools: Evidence from Boston's Charters and Pilots," Quarterly Journal of Economics, 126(2): 699-748.

Abdulkadiroğlu, A., Y. Che, and Y. Yasuda (2011). "Resolving Conflicting Preferences in School Choice: the Boston Mechanism Reconsidered," American Economic Review, 101(1): 399-410.

Abdulkadiroğlu, A., P. Pathak, and A. Roth (2009). "Strategy-Proofness versus Efficiency in Matching with Indifferences: Redesigning the NYC High School Match." American Economic Review, 99(5): 1954-78.

Abdulkadiroğlu, A., P. Pathak, A. Roth and T. Sönmez (2005). "The Boston Public School Match," American Economic Review, Papers and Proceedings, 95(2): 368-371.

\footnotetext{
${ }^{71}$ Ries and Somerville (2010) exploit changes in the catchment areas of public schools in Vancouver and find significant effects of school performance on housing prices. Epple and Romano (2003) conjecture that school choice systems can eliminate the capitalization of school quality on the housing market. Machin and Salvanes (2010) exploit policy reforms in Oslo that allowed students to attend schools without having to live in the school's catchment area, and find a significant decrease in the correlation between a school's quality and housing prices.
} 
Abdulkadiroğlu, A., P. Pathak, A. Roth and T. Sönmez (2006). "Changing the Boston School Choice Mechanism: Strategy-proofness as Equal Access," National Bureau of Economic Research Working Paper 11965.

Abdulkadiroğlu, A., and T. Sönmez (2003). "School Choice: A Mechanism Design Approach," American Economic Review, 93(3): 729-747.

Agarwal, N. and P. Somaini (2015). "Demand Analysis Using Strategic Reports: An Application to a School Choice Mechanism," Working Paper MIT.

Akyol, E. (2014). "Welfare Comparison of School Choice Mechanisms under Incomplete Information," Working Paper Pennsylvania State University.

Arcidiacono, P. (2005). "Affirmative Action in Higher Education: How Do Admission and Financial Aid Rules Affect Future Earnings?" Econometrica, 73(5): 1477-1524.

Azevedo, E. and J. Hatfield (2015). "Existence of Equilibrium in Large Matching Markets with Complementarities," Mimeo, Wharton.

Azevedo, E. and J. Leshno (2015). "A supply and demand framework for two-sided matching markets" forthcoming, Journal of Political Economy

Bajari, P. and A. Hortacsu (2005) "Are Structural Estimates of Auction Models Reasonable? Evidence from Experimental Data," Journal of Political Economy 113, 703-741.

Black, S. and S. Machin (2010) "Housing Valuations of School Performance" in E. Hanishek, S. Machin and L. Woessmann (eds.), Handbook of the Economics of Education, Amsterdam: Elsevier.

Blume, L., W. Brock, S. Durlauf and Y. Ioannides (2011). "Identification of Social Interactions," Handbook of Social Economics, ed. by J. Benhabib, A. Bisin and M. Jackson, North-Holland, Vol 1B: 853-964.

Burgess, S., E. Greaves, A. Vignoles and D. Wilson (2009). "Parental Choice of primary school in England: what type of schools do parents choose?" CMPO Working Paper No. 09/224.

Calsamiglia, C., M. Güell (2014). "The Illusion of Choice: Evidence from Barcelona," CEPR Discussion Paper 10011. 
Calsamiglia, C. and Miralles A. (2014). "All about priorities? Less choice with bad schools," mimeo UAB.

Chen, Y., and T. Sönmez (2006). "School Choice: An Experimental Study," Journal of Economic Theory, 127(1): 202-231.

Deming, D., J. Hastings, T. Kane, and D. Staiger (2014). "School Choice, School Quality and Postsecondary Attainment," American Economic Review, 104(3): 9911013.

Epple, D. and R. Romano (2003). "Neighborhood Schools, Choice, and the Distribution of Educational Benefits," in C. Hoxby (ed), The Economics of School Choice, University of Chicago Press.

Epple, D. and R. Romano (2011). "Peer effects in education : a survey of the theory and evidence," Handbook of Social Economics, ed. by J. Benhabib, A. Bisin and M. Jackson, North-Holland, Vol 1B: 1053-1163.

Ergin, H., and T. Sönmez (2006). "Games of School Choice under the Boston Mechanism," Journal of Public Economics, 90(1-2): 215-237.

Dur, U., S. Kominers, P. Pathak and T. Sönmez (2013). "The Demise of Walk Zones in Boston: Priorities vs. Precedence in School Choice," NBER Working Paper No. 18981.

Featherston, C. and M. Niederle (2008). "Ex Ante Efficiency in School Choice Mechanisms: An Experimental Investigation," NBER Working Paper 14618.

Fu, C. (2014). "Equilibrium Tuition, Applications, Admissions and Enrollment in the College Market," Journal of Political Economy, 122(2): 225-281.

Gibbons, S. and S. Machin (2008) "Valuing School Quality, Better Transport and Lower Crime," Oxford Review of Economic Policy, 24: 99-119.

Hastings, J., T. Kane and D. Staiger (2009). "Heterogeneous Preferences and the Efficacy of School Choice," NBER Paper Working Paper 12145.

Hastings, J. and J. Weinstein (2008) "Information, School Choice and Academic Achievement: Evidence from Two Experiments," Quarterly Journal of Economics, 1373-1414. 
Hatfield, J., F. Kojima, and Y. Narita (2014), "Promoting School Competition through School Choice: A Market Design Approach," Mimeo, Stanford University.

He, Y. (2014). "Gaming the Boston School Choice Mechanism in Beijing," Working Paper, Toulouse School of Economics.

Heckman, J. and S. Mosso (2014). "The Economics of Human Development and Social Mobility," Working paper, University of Chicago.

Hoxby, C. (2003): "School Choice and School Productivity (Or, Could School Choice be a Rising Tide that Lifts All Boats)," in The Economics of School Choice, ed. by C. Hoxby. Chicago: University of Chicago Press.

Hwang, S. (2015). "A Robust Redesign of High School Match," Working Paper, UBC. Jensen, R. (2010). "The (Perceived) Returns to Education and the Demand for Schooling," Quarterly Journal of Economics, 125 2, 515-548.

Keane, M. and R. Moffitt (1998). "A Structural Model of Multiple Welfare Program Participation and Labor Supply.” International Economic Review 39, 553-590.

Keane, M., P. Todd and K. Wolpin (2011) "The Structural Estimation of Behavioral Models: Discrete Choice Dynamic Programming Methods and Applications," in: O. Ashenfelter and D. Card (Eds.) Handbook of Labor Economics, North-Holland. Vol 4A: 331-461.

Keane, M. and K. Wolpin (2007). "Exploring the Usefulness of a Non-random Holdout Sample for Model Validation: Welfare Effects on Female Behavior," International Economic Review 48, 1351-1378.

Kojima, F. (2015). "Recent Developments in Matching Theory and their Practical Applications," Manuscript, Stanford University.

Kominers, S. and T. Sönmez (2012). "Designing for Diversity: Matching with SlotSpecific Priorities," Boston College Working Paper No. 806.

Lavy, V. (2010) "Effects of Free Choice Among Public Schools." The Review of Economic Studies, 77: 1164-1191. 
Lewbel, A. (2000). "Semiparametric qualitative response model estimation with unknown heteroscedasticity or instrumental variables," Journal of Econometrics, 97: 145-177.

Lise, J., S. Seitz, and J. Smith (2005). "Equilibrium Policy Experiments and the Evaluation of Social Programs," Mimeo, Queens University.

Lu, J. (2014). "Cardinal Utility and Incomplete Information in School Choice: Strengthening the Case for the Boston Mechanism," Undergraduate Thesis, Harvard University.

Lumsdaine, R., J. Stock, and D. Wise (1992). "Pension Plan Provisions and Retirement: Men and Women, Medicare, and Models," In: Wise, D.A. (Ed.), Studies in the Economics of Aging, University of Chicago Press, Chicago.

Machin, S., and K. G. Salvanes (2010). "Valuing School Quality via School Choice Reform," IZA Discussion Paper No 4719.

Matzkin, R. (1993). "Nonparametric Identification and Estimation of Polychotomous Choice Models," Journal of Econometrics, 58: 137-168.

McFadden, D., and A. Talvitie (1977). "Validation of Disaggregate Travel Demand Models: Some Tests," Urban demand forecasting project, final report. Vol. V, Institute of Transportation Studies, University of California, Berkeley.

Mehta, N. (2013). "Competition in Public School Districts: Charter School Entry, Student Sorting, and School Input Determination," Working paper, UWO.

Miralles, A. (2008). "School Choice: The Case for the Boston Mechanism," Mimeo, Barcelona Graduate School of Economics.

Pais, J., and A. Pinter (2008). "School Choice and Information: An Experimental Study on Matching Mechanisms," Games and Economic Behavior, 64(1): 303-38.

Pathak, P. and P. Shi (2014). "Demand Modeling, Forecasting, and Counterfactuals," NBER working paper.

Pathak, P. and T. Sönmez (2008). "Leveling the Playing Field: Sincere and Sophisticated Players in the Boston Mechanism," American Economic Review, 98(4): $1636-52$. 
Pathak, P. and T. Sönmez (2013). "School Admissions Reform in Chicago and England: Comparing Mechanisms by their Vulnerability to Manipulation," American Economic Review, 103(1): 80-106.

Ries, J. and T. Somerville (2010). "School Quality and Residential Property Values: Evidence from Vancouver Rezoning," Review of Economics and Statistics, 92(4), 928944.

Rothstein, J. (2006). "Good Principals or Good Peers: Parental Valuation of School Characteristics, Tiebout Equilibrium, and the Incentive Effects of Competition Among Jurisdictions," American Economic Review, 96(4): 1333-1350.

Todd, P. and K. Wolpin (2006). "Assessing the Impact of a School Subsidy Program in Mexico: Using a Social Experiment to Validate a Dynamic Behavioral Model of Child Schooling and Fertility." American Economic Review 96, 1384-1417.

Troyan, P. (2012). "Comparing School Choice Mechanisms by Interim and Ex-ante Welfare," Games and Economic Behavior, 75(2): 936-947.

Walters, C. (2013). "A Structural Model of Charter School Choice and Academic Achievement," Working paper, UC-Berkeley.

Wise, D. (1985). "A Behavioral Model versus Experimentation: the Effects of Housing Subsidies on Rent." In: Brucker, P. and R. Pauly (Eds.), Methods of Operations Research, 50: 441-489.

\section{Appendix}

\section{A1. Detailed Functional Forms}

Household: $x_{i}=\left[x_{i 1}, \ldots, x_{i 5}\right] . x_{i 1}=I\left(\right.$ edu $_{i}<$ High school $), x_{i 2}=I\left(\right.$ edu $\left._{i}=\mathrm{HS}\right)$, $x_{i 3}=I\left(\right.$ edu $\left._{i}>\mathrm{HS}\right), x_{i 4}=I\left(\right.$ single parent $\left._{i}=1\right), x_{i 5}=\operatorname{sibling's~school~}\left(x_{i 5}=0\right.$ if outside school, $\in\{1, \ldots J\}$ if non-private school, -9 if no sibling).

School: $w_{j}=\left[w_{j 1}, w_{j 2}, w_{j 3}, w_{j 4}\right]$. $w_{j 1}$ : school quality, $w_{j 2}$ : tuition, $w_{j 3}$ : capacity, $w_{j 4}=1$ if semi-public, 0 otherwise.

Zone: $N_{z}$ : \# of schools in zone $z, \bar{q}_{z}$ : the average school quality in $z$.

A1.1 Utility: Preference heterogeneity is captured via 3 channels: 1) general school values relative to the outside option vary with $x ; 2$ ) trade-offs among distance, quality, 
tuition and unobserved school characteristics vary with education; 3) idiosyncratic tastes. Define $g^{*}(\cdot)$ and $C(\cdot)$ such that $U\left(w_{j}, x_{i}, d_{i j}, \zeta_{j}\right)=g^{*}\left(w_{j}, x_{i}, \zeta_{j}\right)-C\left(d_{i j}\right)$,

$$
\begin{gathered}
C\left(d_{i j}\right)=\left[d_{i j}+c_{1} d_{i j}^{2}+c_{2} I\left(d_{i j}>5\right)+c_{3} I\left(d_{i j}>10\right)\right] . \\
g^{*}\left(w_{j}, x_{i}, \zeta_{j}\right)=\tau_{1} x_{i 4}+\tau_{2}\left[I\left(x_{i 5}=j\right)-I\left(x_{i 5}=0\right)\right] \\
+\sum_{m=1}^{3} x_{i m}\left(\delta_{0 m}+\delta_{1 m} \zeta_{j}\right)+w_{j 1}\left(\sum_{m=1}^{3} \alpha_{m} x_{i m}\right)+w_{j 2}\left(\sum_{m=1}^{3} \alpha_{3+m} x_{i m}\right) \\
+\alpha_{7} w_{j 3}+\alpha_{8} w_{j 3}^{2}+\alpha_{9} w_{j 1}^{2}+w_{j 4}\left(\sum_{m=1}^{3} \alpha_{9+m} x_{i m}\right) .
\end{gathered}
$$

The last two rows are education-specific preference for $w_{j}$ and $\zeta_{j}$, with the form of

$$
\sum_{e}\left(\delta_{0 e}+\delta_{1 e} \zeta_{j}+w_{j} \alpha_{e}\right) I\left(e d u_{i}=e\right)
$$

\section{A1.2 Type distribution}

$$
\lambda\left(x_{i}, l_{i}\right)=\lambda\left(x_{i}, z_{l_{i}}\right)=\frac{\exp \left(\beta_{0}+\sum_{m=1}^{4} \beta_{m} x_{i m}+\beta_{5} I\left(x_{i 5} \geq 0\right)+\beta_{6} N_{z_{l_{i}}}+\beta_{7} \bar{q}_{z_{l_{i}}}\right)}{1+\exp \left(\beta_{0}+\sum_{m=1}^{4} \beta_{m} x_{i m}+\beta_{5} I\left(x_{i 5} \geq 0\right)+\beta_{6} N_{z_{l_{i}}}+\beta_{7} \bar{q}_{z_{l_{i}}}\right)} .
$$

\section{B. Policy Evaluation: The 2007 Reform}

We simulate the outcomes for the 2007 applicants had they lived under the 2006 regime, taking as given the 2006 admissions probabilities. The results can be interpreted in two ways: 1) they are at the individual level, i.e., "what would have happened to a 2007 applicant had she applied in 2006?" 2) assuming that the 2006 and 2007 cohorts are two i.i.d. random samples from the same distribution, the results tell us "what would have happened to all 2007 households without the reform and if they had played the same equilibrium as the 2006 cohort?" Table A6 shows that $17 \%$ of households gained and $7 \%$ of them lost from the reform, with more non-strategic households affected. Overall, the gain from the reform was equivalent to 1,430 euros.

\section{Additional Tables ${ }^{72}$}

\footnotetext{
${ }^{72}$ As mentioned in the model section, there can be multiple lists that are payoff-equivalent and imply the same allocation results. All these lists have identical ordered elements that are allocationrelevant, which is what our model can explain. For example, consider a list of length 4, the third element of which was a leftover school. Our model is designed to replicate the first three elements
} 
Table A1 Model Fit: Relevant List Length (\%)

\begin{tabular}{lcccc}
\hline \hline \multicolumn{4}{c}{2006} & \multicolumn{2}{c}{2007} \\
& Data & Model & Data & Model \\
1 & 85.8 & 83.1 & 86.1 & 83.2 \\
2 & 11.5 & 14.5 & 11.7 & 10.3 \\
$\geq 3$ & 2.7 & 3.4 & 2.2 & 6.5 \\
\hline
\end{tabular}

Table A2 Model Fit: Assignment Round (\%)

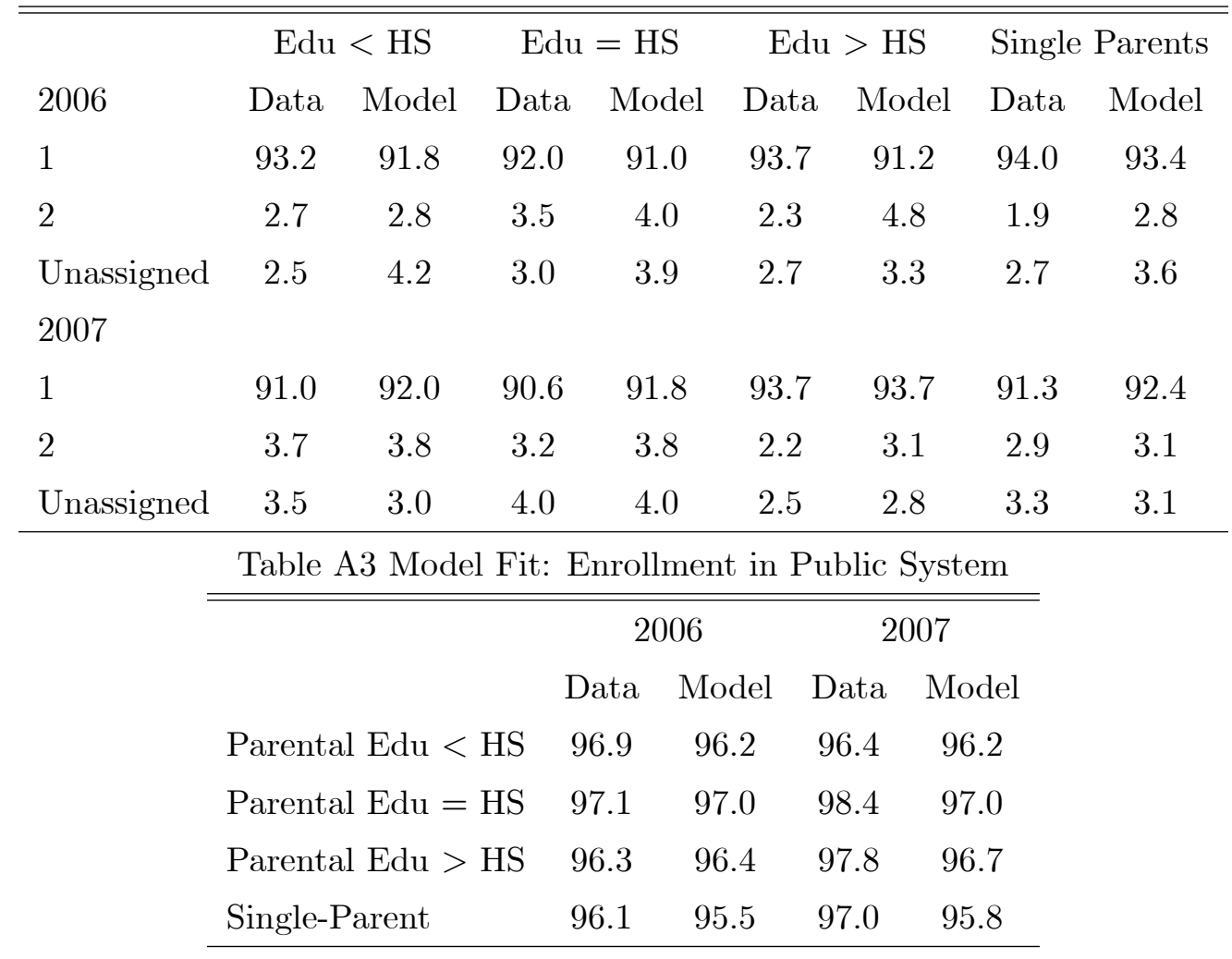

of that list, not how many schools would be listed beyond that point. Table 12 presents the model fit for the length of the allocation-relevant part of household application lists. 
Table A4 Model Fit: Top-Listed Schools

\begin{tabular}{lcccccc}
\hline \hline & \multicolumn{2}{c}{ Quality } & \multicolumn{2}{c}{ Distance $(100 \mathrm{~m})$} & \multicolumn{2}{c}{ Tuition (100 Euros) } \\
& Data & Model & Data & Model & Data & Model \\
Parental Edu < HS & 7.6 & 7.6 & 5.2 & 6.0 & 5.4 & 5.7 \\
Parental Edu = HS & 7.9 & 7.9 & 7.0 & 7.1 & 8.1 & 8.3 \\
Parental Edu > HS & 8.2 & 8.2 & 8.7 & 8.2 & 9.9 & 9.6 \\
Single-Parent & 8.0 & 8.0 & 8.1 & 8.0 & 8.6 & 8.6 \\
2007 & & & & & & \\
Parental Edu < HS & 7.5 & 7.6 & 5.2 & 5.9 & 5.3 & 5.4 \\
Parental Edu = HS & 8.0 & 7.9 & 6.3 & 6.8 & 8.2 & 8.0 \\
Parental Edu > HS & 8.2 & 8.2 & 7.8 & 8.2 & 9.7 & 9.5 \\
Single-Parent & 8.0 & 8.0 & 6.8 & 7.2 & 8.2 & 8.0 \\
\hline
\end{tabular}

Table A5 School Assignment: BM

\begin{tabular}{lccc}
\hline \hline & Quality & Distance (100m) & Fees (100Euros) \\
All & $7.8(0.7)$ & $7.3(7.9)$ & $7.7(7.4)$ \\
Edu $<$ HS & $7.4(0.7)$ & $6.6(6.9)$ & $5.2(6.2)$ \\
Edu $=$ HS & $7.8(0.6)$ & $7.1(7.2)$ & $7.7(7.1)$ \\
Edu $>$ HS & $8.0(0.7)$ & $8.1(8.3)$ & $9.3(8.0)$ \\
\hline
\end{tabular}

Table A6 Impact of the 2007 Reform

\begin{tabular}{lcccc}
\hline \hline & Winner $(\%)$ & Loser $(\%)$ & $\Delta$ utils & $\Delta$ 100 Euros \\
All & 16.7 & 6.7 & $6.7(29.5)$ & $14.3(68.4)$ \\
Strategic & 16.6 & 6.5 & $6.6(28.7)$ & $14.1(65.9)$ \\
Non-strategic & 20.8 & 11.9 & $8.2(43.8)$ & $18.9(108.4)$ \\
Edu $<$ HS & 14.7 & 7.0 & $4.9(25.7)$ & $5.0(26.0)$ \\
Edu $=$ HS & 18.1 & 7.7 & $7.1(31.0)$ & $22.9(99.8)$ \\
Edu $>$ HS & 17.1 & 5.9 & $7.6(30.6)$ & $13.7(55.2)$ \\
\hline${ }^{*}$ Compare the welfare of a 2007 household under the 2007 regime with its would-be \\
welfare under the 2006 regime. Winners have higher welfare under the 2007 regime.
\end{tabular}

